\title{
Further characterization of adult sheep ovarian stem cells and their involvement in neo-oogenesis and follicle assembly
}

Hiren Patel, Deepa Bhartiya* and Seema Parte

\begin{abstract}
Background: Stem cells in the ovary comprise of two distinct populations including very small embryonic-like stem cells (VSELs) and slightly bigger progenitors termed ovarian stem cells (OSCs). They are lodged in ovary surface epithelium (OSE) and are expected to undergo neo-oogenesis and primordial follicle (PF) assembly in adult ovaries. The ovarian stem cells express follicle stimulating hormone (FSH) receptors and are directly activated by FSH resulting in formation of germ cell nests (GCN) in vitro. Present study was undertaken to further characterize adult sheep OSCS and to understand their role during neo-oogenesis and PF assembly.

Methods: Stem cells were collected by gently scraping the OSE cells and were characterized by H\&E staining, immuno-localization, immuno-phenotyping and RT-PCR studies. Expression of FSH receptors and markers specific for stem cells (OCT-4, SSEA-4) and proliferation (PCNA) were studied on stem/progenitor cells in OSE culture and on adult sheep ovarian cortical tissue sections. Effect of FSH on stem cells was also studied in vitro. Asymmetric cell division (ACD) was monitored by studying expression of OCT-4 and NUMB.

Results: Additional evidence was generated on the presence of two populations of stem cells in the OSE including VSELs and OSCS. FSHR expression was observed on both VSELs and OSCs by immuno-localization and immuno-phenotyping studies. FSH treatment in vitro stimulated VSELs that underwent ACD to self-renew and give rise to OSCs which divided rapidly by symmetric cell divisions (SCD) and clonal expansion with incomplete cytokinesis to form GCN. ACD was further confirmed by differential expression of OCT-4 in VSELs and NUMB in the OSCs. Immuno-histochemical expression of OCT-4, PCNA and FSHR was noted on stem cells located in the OSE in sheep ovarian sections. GCN and cohort of PF were observed in the ovarian cortex and provided evidence in support of neo-oogenesis from the stem cells.
\end{abstract}

Conclusion: Results of present study provide further evidence in support of two stem cells populations in adult sheep ovary. Both VSELS, OSCS and GCN express FSH receptors and FSH possibly regulates their function to undergo neo-oogenesis and primordial follicle assembly.

Keywords: Ovary, Stem cells, FSH, Primordial follicle, VSELs, OCT-4, FSHR

* Correspondence: deepa.bhartiya@yahoo.in

Stem Cell Biology Department, ICMR-National Institute for Research in

Reproductive Health, Jehangir Merwanji Street, Parel, Mumbai 400 012, India 


\section{Background}

General consensus exists among reproductive biologists that a mammalian ovary has finite number of follicles at birth that get depleted over time and a sudden depletion of follicles with age leads to menopause [1]. Several groups have reported ovarian stem cells (OSCs) in adult mammalian ovary that are expected to undergo neo-oogenesis and primordial follicle assembly just like spermatogenesis in testis and menopause occurs probably due to compromised somatic niche with age that becomes unable to support normal differentiation of stem cells and primordial follicle assembly $[2,3]$. However, a consensus on the very existence of OSCs in adult ovaries [4] and evidence in support of their in vivo role during neo-oogenesis and follicle assembly is yet to emerge. Our group recently made an attempt to resolve existing controversies in the field of ovarian stem cells [5].

Presence of OSCs and neo-oogenesis was first reported by Tilly's group in 2004 who demonstrated the presence of 5-8 $\mu \mathrm{m}$ OSCs in ovary surface epithelium (OSE) and the work done on these stem cells was compiled $[6,7]$. Virant-Klun's group has reported the presence of smaller 3-5 $\mu \mathrm{m}$ SSEA-4 positive stem cells in human OSE expressing several pluripotent and primordial germ cells (PGCs) specific markers and their ability to spontaneously differentiate into oocytes-like structures in vitro $[8,9]$. Our group reported the presence of two distinct populations of stem cells in OSE comprising smaller 3$5 \mu \mathrm{m}$ very small embryonic-like stem cells (VSELs) expressing nuclear OCT-4 and other pluripotent and PGCs specific markers and another population of slightly bigger 5-8 $\mu \mathrm{m}$ progenitors which were termed ovarian germ stem cells (OGSCs) and are similar to OSCs reported by Tilly's group (Additional file 1: Figure S1) and will be henceforth termed OSCs in the manuscript. The OSCs are reported to express cytoplasmic OCT-4 in humans, sheep, marmoset and rabbit ovaries [10, 11] and also in mouse ovaries [12]. Presence of two distinct populations of stem cells in the OSE was recently discussed [5, 13] and the methods to isolate and characterize both populations of stem cells including primitive VSELs and progenitor OSCs have been published [14]. Similar VSELs were also reported in human [15] and mouse [16-18] testes which exist as a subgroup amongst the well-studied spermatogonial stem cells (SSCs). Thus a similar population of VSELs exists along with OSCs in ovary and SSCs in the testis. VSELs are the most primitive, relatively quiescent, epiblast derived pluripotent stem cells equivalent to primordial germ cells (PGCs) that survive in adult gonads in few numbers and were recently reviewed [19, 20]. OSCs/ SSCs are tissue specific progenitors that are bigger in size and have a distinct gene expression pattern compared to pluripotent VSELs. Data is now emerging suggesting that tissue specific stem cells like SSCs in testis [17] and hematopoietic stem cells (HSCs) in the bone marrow [21] arise by asymmetric cell division (ACD) of VSELs and in turn undergo symmetric cell divisions (SCD) and clonal expansion (sphere formation) before differentiating into tissue specific cell types including sperm in testis and blood cells in the bone marrow. How do these stem cells function in vivo in adult mammalian ovaries and what intrinsic factors activate and regulate their biology? These are questions that need to be answered.

Hypothalamus and pituitary gonadal axis plays an important role in both male and female reproductive biology. Pituitary gonadotropin, follicle stimulating hormone (FSH) is central to mammalian reproduction and is known for its pleiotropic action not only in gonads but also in extra gonadal tissues [22, 23]. FSH acts through its receptors (FSHR) that are reported to have splice variant isoforms [24]. We have earlier reported that FSH exerts a direct action on the stem cells both in vivo in mice ovaries [12] and testis [17] as well as in vitro on sheep [11], mouse [12] marmoset and human [10] ovarian and mouse testicular [17] cells. FSH stimulates VSELs to undergo ACD to give rise to SSCs which proliferate and undergo clonal expansion as chains in testis and give rise to OSCs that undergo germ cell nest formation in the ovary. FSHR expression has also been reported on stem/progenitor cells in both ovary and testis $[11,17]$. These results were arrived at using 3 different FSHR antibodies, by peptide blocking to confirm specificity of FSHR expression on stem cells and also by qRTPCR and in situ hybridization at mRNA level [15].

It is intriguing to note that VSELs and HSCs in the hematopoietic system also express FSHR in mouse bone marrow [21-25] as well as in human cord blood [26, 27]. Shaikh et al. [28] reported FSHR on bone marrow stem cells and that FSH treatment to chemoablated (5flourouracil, $150 \mathrm{mg} / \mathrm{Kg}$ ) mice augmented the process of bone marrow re-colonization by 72 h. ZbuckaKretowska et al. [27] reported that VSELs and HSCs (and not endothelial progenitors) are mobilized into the peripheral blood of female patients undergoing FSH therapy for stimulating ovaries in an IVF clinic. These findings suggest that a common pool of VSELs exists in various adult organs with a developmental link to PGCs and this explains FSHR expression in non-gonadal tissues as well.

Difference of opinion exists in the literature on the presence of OSCs due to the use of DDX as a marker to sort OSCs for various studies [29]. However, these controversies surrounding the presence of OSC are purely technology related and stem cells do exist in adult ovaries. Generally, the ovarian tissue is subjected to enzymatic digestion and then centrifuged to obtain a cell 
pellet (containing stem cells) for various experiments. The OSCs lodged in the OSE get diluted in overall population of cells obtained after digestion and VSELs (which exist in very few numbers and are small in size compared to the somatic cells) most likely get discarded while processing as discussed recently [19]. Rather than using the whole ovary for Fluorescent-Activated (FACS) or Magnetic-Activated Cell Sorting (MACS) to isolate OSCs, we manually scrape the ovarian surface of higher mammals (sheep, rabbit, marmoset, human) and partial enzymatic digestion of mice ovaries to obtain OSE cells in a culture dish taking care to always spin at a speed of $1000 \mathrm{~g}$ which is crucial to pellet VSELs [19]. Cell suspension thus obtained is used to characterize OSCs by various techniques like flow cytometry, Hematoxylin and Eosin (H\&E), immuno-staining and RT-PCR. Apart from DDX-4, one could also use markers like OCT-4 and SSEA-4 to study stem cells in OSE. Guo et al. [30] have recently provided strong evidence in support of active germ cells in adult mouse ovary by using Oct- 4 transgenic mouse as study model. They detected persistent DNA reduplication, mitosis and entry into meiosis and progression to primordial follicle in young adult mice ovaries over a period of 4 months. Results were confirmed by immuno-expression, RT-PCR and BrdU uptake studies. Moreover, Zhang and Wu [31] established a cell line of double positive (DDX4 and EdU) cells from young adult 21 days old Ddx4-Cre; $\mathrm{mT} / \mathrm{mG}$ mouse ovaries and these cells were able to produce an offspring on transplanting in sterilized recipients after mating.

The present study was undertaken to gain further insights into adult sheep OSCs biology and also to delineate how these stem cells may function in vivo. Sheep ovaries were preferred for the studies as they are bigger in size, more close to human ovaries and available in plenty from a slaughter house. We have generated evidence in support of presence of two populations of stem cells including VSELs and OSCs. Ovarian stem cells were further studied for the expression of pluripotent/ progenitor stem cell markers and FSHR and direct effect of FSH was studied on the stem cells in vitro. We also studied differential expression of OCT-4 and NUMB to delineate whether the primitive VSELs undergo ACD to self-renew and give rise to OSCs. Besides, sheep ovarian cortical tissue sections were studied to detect stem cells and to gather evidence in support of postnatal neooogenesis and primordial follicle assembly in situ.

\section{Methods}

The study was approved by Institute Committee for Stem Cell research (ICSCR) and Animal Ethics (IAEC) committee. Sheep ovaries were transported from a local slaughter house in $0.9 \%$ normal saline containing Penicillin $100 \mathrm{U} /$
$\mathrm{mL}$ and Streptomycin $100 \mu \mathrm{g} / \mathrm{mL}$ (Invitrogen, USA) at room temperature (RT) and used for various studies.

\section{Details of various experiments undertaken in the present study}

Sheep ovary is big in size, tough and fibrous compared to mouse ovary and can be easily held with forceps for scraping of OSE cells. The cortex does not get damaged and the chances of presence of contaminating granulosa cells are minimal. RT-PCR studies were undertaken to detect granulosa cells specific markers Amh and Gata-4 in the scraped OSE cells. Once it was ensured that the scraped OSE cells (enriched for stem cells) were not contaminated by granulosa cells, 3 major experiments were undertaken as mentioned below.

A. Characterization of stem cells in sheep OSE: The stem cells in the OSE were characterized by immuno-phenotyping studies wherein OCT-4 positive stem cells were enumerated by using tagged and untagged OCT-4 antibody. Co-expression of FSHR and OCT-4 was also studied. Expression of OCT-4, SSEA-4 and FSHR on the stem cells was studied by immunofluorescence studies. RT-PCR detection for transcripts specific for stem/progenitor cells and their proliferation was carried out using primers specific for Oct-4A, Sox-2, Oct-4, Vasa, Stat3 and Pcna. Antibody used to study OCT-4 is able to detect both the alternatively spliced OCT-4 isoforms including OCT-4A in the nucleus of VSELs and OCT-4B in the cytoplasm of the OSCs as described earlier also [15].

B. Effect of FSH treatment on sheep ovarian stem cells in vitro: OSE cells were cultured for $24 \mathrm{~h}$ in presence and absence of FSH (rFSH, Gonal F, Merck Serono, Switzerland). The epithelial cells get attached to the surface of the culture dish whereas stem cells remain non-adherent. Cultured cells were used to make smears to study expression of OCT-4, SSEA-4 and FSHR and for RNA extraction to study differential effect of FSH on Oct-4A, Sox-2, Oct-4, Vasa, Stat-3 and Pcna by qRT-PCR. Although Stat-3 is not a specific stem cell marker but its expression in OSE reflects presence of proliferating stem cells [32]. Dividing cells of unequal sizes suggestive of ACD were observed after FSH treatment and were studied for the co-expression of NUMB and OCT-4. Nuclear OCT-4 is a stem cell marker whereas NUMB was used to distinguish stem/ progenitor cells. NUMB is known to suppress Notch signaling essential for maintaining undifferentiated stem cells [33]. During ACD, whereas the other smaller cell retains stem cell state and expresses nuclear OCT-4A, the bigger progenitors is expected to express NUMB and 
should be negative for nuclear OCT-4A. Thus during ACD in the ovarian stem cells, it is expected that the smaller VSEL will express nuclear OCT-4A and the slightly bigger OSC will express NUMB. Similar ACD has been reported in testicular [17] and bone marrow [21] stem cells. Ganguly et al. [21] recently reported differential expression of OCT -4 and NUMB during ACD in mouse bone marrow stem cells.

C. Studies on sheep ovarian sections: Ovarian sections were used to study histology and expression of PCNA, OCT-4 and FSHR. This study helped us to gather evidence how stem cells may function in vivo in adult ovary.

Details of various methods used in the present study Few ovaries were fixed in 10\% neutral buffered formalin (NBF) at $4{ }^{\circ} \mathrm{C}$ for histological studies and immunohistochemistry. Ovaries were also used to manually scrape OSE cells used for various studies using methods described in details below. Additional file 1: Tables S1 and S2 show details of antibodies and primers used for the study.

\section{Isolation of OSE cells}

Ovaries were rinsed 3-5 times with calcium and magnesium free Dulbecco's phosphate-buffered saline (DPBS; Invitrogen) containing antibiotics (1X PenStrep). Surrounding extraneous tissue was removed without disturbing the OSE layer. Ovaries were placed in DMEM/ F12 high-glucose (Sigma-Aldrich, USA) with 1X antibiotics and their surface was gently scraped with the help of a sterile blunt cell scraper to release the OSE cells as described earlier [10, 11]. These OSE cells were filtered through $40 \mu \mathrm{m}$ sieve (BD Bio Sciences, USA) and were washed using $1 \mathrm{X}$ PBS by spinning cells suspension at $1000 \mathrm{~g}$ for $10 \mathrm{~min}$ at RT. Cell pellets were re-suspended in $1 \mathrm{X}$ PBS or plain DMEMF12 medium and used to make smears, for RNA extraction, flow cytometry and culture studies.

\section{Preparation of sheep OSE cell smears}

OSE cells smears were prepared on poly-L-lysine (Sigma-Aldrich,) coated slides. Cells were air dried on the glass slides, fixed with $4 \%$ paraformaldehyde (PFA; Sigma-Aldrich) for $15 \mathrm{~min}$ followed by 3 to 4 washes with 1 XPBS. Slides were then air dried and stored at $4^{\circ}$ $\mathrm{C}$ until further use. Smears were used for H\&E staining to study different cell types and also for immunolocalization studies (OCT-4, SSEA-4, FSHR \& VASA).

\section{Culture of OSE cells}

The OSE cells were collected in DMEM/F12 medium supplemented with $10 \%$ fetal bovine serum (FBS, Invitrogen,) with antibiotics and were cultured in $5 \% \mathrm{CO}_{2}$ incubator at $38.5{ }^{\circ} \mathrm{C}$ with or without $\mathrm{FSH}(5 \mathrm{IU} / \mathrm{ml}$, Gonal F). Effect of FSH treatment on ovarian stem cells was studied by $\mathrm{H} \& \mathrm{E}$ staining, immuno-localization (OCT-4, SSEA-4, VASA, FSHR, PCNA) and qRT-PCR (Oct-4A, Sox-2, Stat-3, Total Oct-4, Vasa, Fshr1 and Fshr3) and proliferation (Pcna) specific markers with and without FSH.

\section{Immuno-localization studies}

Immuno-fluorescence (IF): For IF studies, the OSE smears were hydrated in $1 \mathrm{X}$ PBS, followed by $2 \mathrm{~h}$ blocking in PBS containing 10\% normal goat serum (NGS) and 1\% bovine serum albumin (BSA) (Sigma-Aldrich). After removing excess blocking solution, the smears were incubated overnight with primary antibody against FSH receptor (1:100), OCT4 (1:100) and SSEA-4 (1:100) at $4{ }^{\circ} \mathrm{C}$. Permeabilization with $0.3 \%$ Triton X (Sigma-Aldrich) was done for 5 min to study nuclear and cytoplasmic expression of OCT-4 prior to incubating with primary antibody. Next day the slides were brought to RT and washed three times (5 mins each wash) with phosphate buffered saline (PBS) to remove excess unbound antibody. Later the cells were incubated with respective secondary antibody Alexa flour (Molecular Probes, Invitrogen) 488 or 568 (1:1000) for $2 \mathrm{~h}$ at RT. The smears were then counterstained with propidium iodide (PI, Sigma-Aldrich; $5 \mathrm{mg} / \mathrm{ml}$ ) for $2 \mathrm{~min}$ or 4' 6-diamidino-2phenylindole (DAPI, Sigma-Aldrich; $1.47 \mu \mathrm{M}$ ) for $20 \mathrm{~min}$. Finally, smears were washed with PBS and mounted using Vectashield and stored at $4{ }^{\circ} \mathrm{C}$ till viewing. The slides were scanned under laser scanning confocal fluorescent microscope (LSM 510-META, ZEISS, Germany) and representative images were photographed.

Immuno-histochemistry (IHC): Briefly, the paraffin embedded ovarian tissue sections were deparaffinized and incubated in xylene for 30 mins. After air drying, the slides were incubated with $3 \%$ hydrogen peroxide (Qualigens, India) in 100\% methanol for $1 \mathrm{~h}$ in dark after which the sections were gradually hydrated in descending series of methanol to tap water for $5 \mathrm{~min}$ each. Antigen retrieval was done by immersing the slides in boiling sodium citrate (SSC, Sigma-Aldrich) buffer at $\mathrm{pH} 6$ for 5 mins. After cooling, the slides were washed with $1 \mathrm{X}$ PBS buffer for $5 \mathrm{~min}$. Permeabilization step was carried out by $0.3 \%$ TritonX-100 in PBS buffer for 5-7 min to studyOCT-4 and PCNA expression. After blocking for $2 \mathrm{~h}$ with $2 \%$ BSA along with $5 \%$ normal goat serum (NGS) for OCT-4 and FSHR antibodies and with 5\% normal horse serum (NHS) for PCNA antibody, the slides were incubated overnight at $4{ }^{\circ} \mathrm{C}$ with OCT-4, FSHR and PCNA antibodies. Next day slides were washed 3 times with PBS (5 min each wash) and then incubated with respective biotinylated secondary antibody for $30 \mathrm{~min}$ followed by avidin biotin complex formation step for $30 \mathrm{~min}$ (Vectastain Elite ABC kit, Vector 
Laboratories Inc., USA), 3 washes with PBS and then color reaction was done using diaminobenzidene (Biogenex, USA). The slides were then counterstained with Hematoxylin, dehydrated, cover slipped and sealed using nail polish. Representative areas were photographed under Nikon 90i microscope (Nikon, Japan).

Immuno-cytochemistry (ICC): For ICC, after the blocking step in dark at room temperature using 3\% hydrogen peroxide in PBS for $30 \mathrm{~min}$, the smears were subjected to antigen retrieval by incubating with sodium citrate buffer (10 $\mathrm{mM}$ sodium citrate), $\mathrm{pH}$ 6.0, at high power for $5 \mathrm{~min}$ in a microwave oven. This was followed by permeabilization step with $0.3 \%$ Triton-X 100 for 10 min. Further procedure for immuno-localization was similar to that described for IHC above.

Primary antibody was omitted in the negative controls for various experiments. To further demonstrate the specificity of FSHR expression on the stem cells, peptide against which FSHR antibody was raised was incubated overnight along with the antibody at $4{ }^{\circ} \mathrm{C}$ and used as another negative control for various experiments.

Flow cytometry studies Immuno-phenotyping studies using sheep OSE cells have earlier [14] shown the presence of two distinct populations of OCT-4 positive stem cells (Additional file 1: Figure S1). In the present study further immuno-phenotyping studies were carried to evaluate OCT-4, and FSHR positive cells in OSE. Briefly, single cells suspension of OSE cells were prepared as described above and were fixed in $2 \%$ PFA for $15 \mathrm{~min}$. The cells were washed twice with PBS and then permeabilized for 5 to 10 min using $0.1 \%$ NP40 solution (Sigma) in PBS for studying OCT-4 expression whereas no permeabilization was done to study cell surface expression of FSHR. Indirect labeling with primary antibodies (OCT-4, FSHR) was performed by incubating cells with them for $60 \mathrm{~min}$ at $4{ }^{\circ} \mathrm{C}$ followed by secondary antibodies (Alexaflour goat anti-mouse IgG 568 or IgG 488) for 45 min (Molecular Probes, Invitrogen). Direct labeling was done for OCT-4 PerCP-Cy tagged antibody (BD, USA) for $45 \mathrm{~min}$ at $4{ }^{\circ} \mathrm{C}$. Following three washes with PBS, the events were acquired and analyzed using FACS DIVA software and FCS Express 4 software (De Novo software). Calibration beads of size 2 to $15 \mu \mathrm{m}$ were used according to the manufacturer's instructions (Life Technologies, USA) as reference for selecting cells ranging from 2 to $6 \mu \mathrm{m}$. Care was taken to spin the cells at $1000 \mathrm{~g}$ while pelleting the cells throughout the experiment since the stem cells do not pellet down at 200-250 $\mathrm{g}[14,19]$.

\section{RNA extraction, RT-PCR and $q R T-P C R$ studies}

RNA was extracted from OSE cells using TRIZOL (Invitrogen) by standard protocol followed by DNase I (Amersham Biosciences, USA) treatment at $37{ }^{\circ} \mathrm{C}$ for $30 \mathrm{~min}$ to remove any genomic DNA contamination. Reverse transcription of cDNA was performed using iScript cDNA synthesis kit (Bio-Rad, USA) according to the manufacturer's instructions. Briefly, RNA was incubated with 5X iScript reaction mix and iScript reverse transcriptase mix. The reaction was carried out in G-STORM thermocycler (Gene Technologies, UK). The reaction mix was first incubated at $25{ }^{\circ} \mathrm{C}$ for $5 \mathrm{~min}$, then at $42{ }^{\circ} \mathrm{C}$ for $30 \mathrm{~min}$ and finally at $85{ }^{\circ} \mathrm{C}$ for $5 \mathrm{~min}$.

RT-PCR was carried out to detect transcripts specific for stem cells (Oct-4A, Sox-2, Stat-3, Total Oct-4, Vasa) and granulosa cells (Amh, Gata-4) along with Gapdh as housekeeping transcript. Briefly, the cDNA was incubated with Taq DNA polymerase, $1.5 \mathrm{~mm} \mathrm{MgCl} 2$ and $10 \mathrm{mM}$ deoxynucleotide triphosphates (Fermentas Life Sciences, USA) with specific primers $(10 \mathrm{pmol})$ in a $25 \mu \mathrm{l}$ reaction volume using G STORM thermocycler. PCR program included initial denaturation at $95^{\circ} \mathrm{C}$ for $3 \mathrm{~min}$, followed by denaturation for $1 \mathrm{~min}$, annealing at different temperatures (Additional file 1: Table S2) and final elongation at $72{ }^{\circ} \mathrm{C}$ for 50 s. for $35-40$ cycles. The RT-PCR products were visualized by electrophoresis on $2 \%$ agarose gel.

The expression levels of various transcripts were also estimated by CFX96 real-time PCR system (Bio-Rad Laboratories, California, USA) using SYBR Green chemistry (Bio-Rad). Gapdh was used as housekeeping in all the experiments. The amplification conditions were described earlier: initial denaturation at $94{ }^{\circ} \mathrm{C}$ for $3 \mathrm{~min}$ followed by 40 cycles comprising of denaturation at $94^{\circ}$ $\mathrm{C}$ for $30 \mathrm{~s}$, primer annealing at specific temperature (Additional file 1: Table S2) for $30 \mathrm{~s}$, and extension at $72{ }^{\circ} \mathrm{C}$ for $30 \mathrm{~s}$. The final extension was carried out for 5 mins at $72{ }^{\circ} \mathrm{C}$. The fluorescence emitted at each cycle was captured during the extension step of each cycle. The homogeneity of the PCR amplicons was verified by running the products on $2 \%$ agarose gels. Each gene amplification was carried out in duplicate. The fold change expression of each transcript was studied from three different experimental replicates.

\section{Results}

Initially it was ensured that only ovary surface epithelial cells and stem cells were collected by the method of gentle scraping of ovary surface (Additional file 1: Figure S2) and there was no contamination by the granulosa cells. For this, RT-PCR for 2 granulosa cell markers (Amh, Gata-4) was carried out and these transcripts were not detected in the OSE cells (Additional file 1: Figure S3). 


\section{Characterization of stem cells in sheep ovary surface epithelium}

\section{Immuno-phenotyping studies}

Immuno-phenotyping studies were undertaken to enumerate cells in the size range of $2-6 \mu \mathrm{m}$ expressing OCT4 using untagged (Fig. 1) and tagged (Fig. 2) antibodies. $4.4 \%$ of cells in the size range of $2-6 \mu \mathrm{m}$ expressed OCT4 by indirect staining method using untagged antibody. $4 \%$ of cells were found positive using directly tagged OCT-4 antibody. Furthermore, $6.5 \%$ of OSE cells in the size range of $2-6 \mu \mathrm{m}$ expressed FSHR and $1.2 \%$ of these cells co-expressed FSHR and OCT-4(Fig. 2).

\section{Immuno-fluorescence studies}

OCT-4, SSEA-4 and FSHR expression was studied on stem cells by confocal microscopy (Fig. 3). Nuclear OCT-4. was found localized in small sized VSELs (Fig. 4Ai) and cytoplasmic OCT-4 in the slightly bigger OSCs (Fig. 3Aii) with PI as nuclear stain and negative control (lacking primary antibody) showed no IF signals (Fig. 3Aiii). Similar staining pattern was observed for SSEA-4 in VSELs (Fig. 3Bi) and OSCs (Fig. 3Bii) with DAPI as nuclear stain and absent signals in negative control (Fig. 3Biii). FSH receptors were localized on the surface of both stem cell populations (Fig. 3c) with DAPI as nuclear stain. Stem cells were found to co-express SSEA-4 and FSHR (Fig. 4a) whereas Fig. $4 \mathrm{~b}$ is negative control. Additional data showing expression of FSHR and co-expression of OCT4/SSEA-4 and FSHR on the ovarian stem cells is provided in the supplement including a Z-stack of OCT-4 expression on stem cells (Additional file 1: Figures S4-S6).

\section{$R T-P C R$ analysis}

RT-PCR analysis on the manually scraped OSE cells showed the presence of transcripts specific for stem/ progenitor cells including Oct-4A, Sox-2, Oct-4, Vasa, Stat 3 and Pcna (Fig. 4c), thus confirming the presence of stem/progenitor cells in OSE.

To conclude from this section, scraped OSE cells comprise epithelial cells, stem cells and few red blood cells and are not contaminated by granulosa cells and thus FSHR expression is on the stem cells. Immunophenotyping studies confirm that stem cells in the size range of 2-6 um exist in OSE that express OCT-4 and a sub-population of these stem cells also express FSHR. OCT-4 and FSHR expression was also confirmed by confocal microscopy and at mRNA level by RT-PCR. FSHR expression on OSCs provides a paradigm shift in current understanding of FSH action. We have earlier reported similar expression of FSHR on testicular stem cells by using 3 different antibodies [17] and thus use of a single antibody in the present study sufficed to show similar presence of FSHR on ovarian stem cells. FSHR detection by qRT-PCR and in situ hybridization using

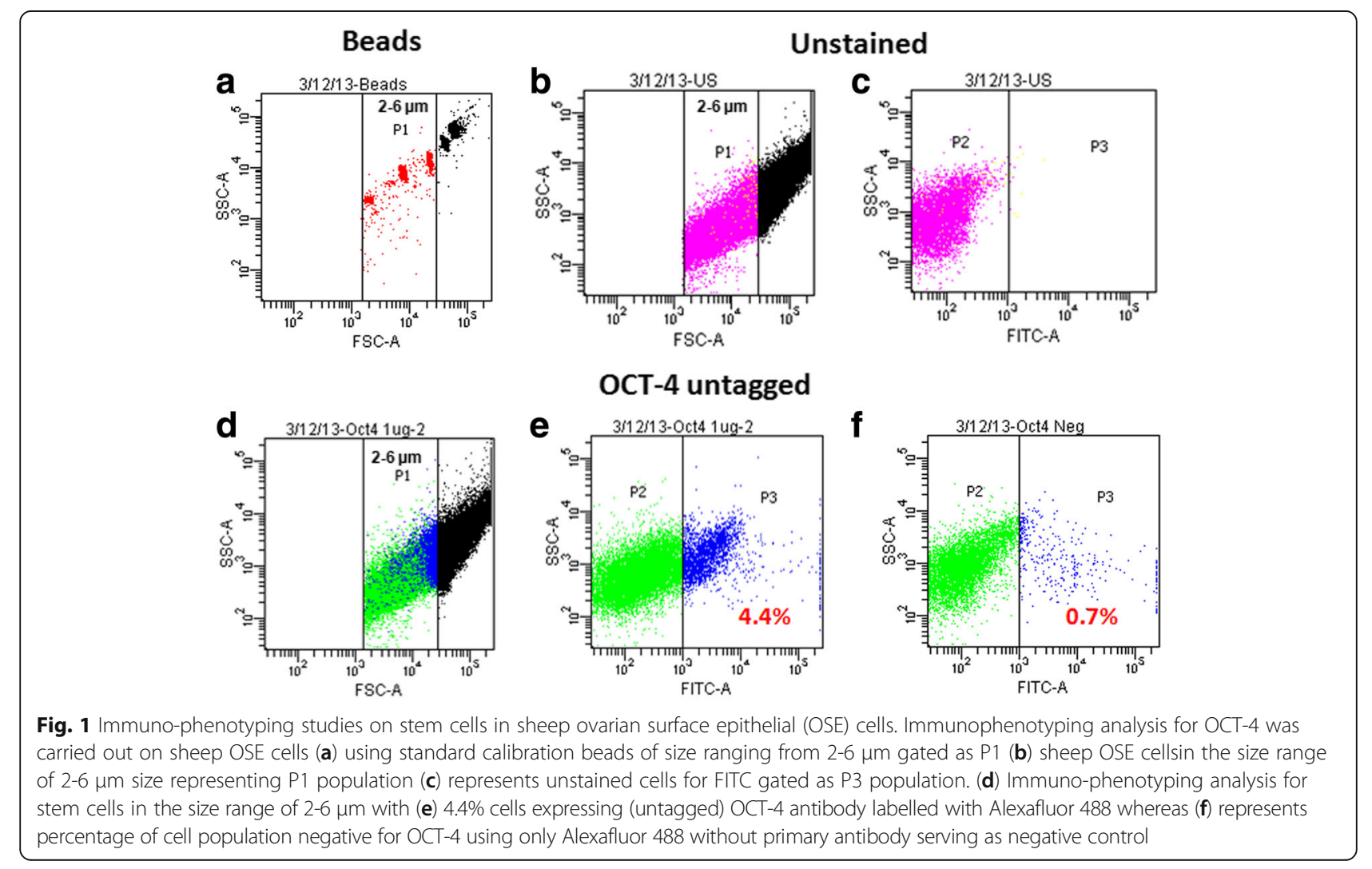




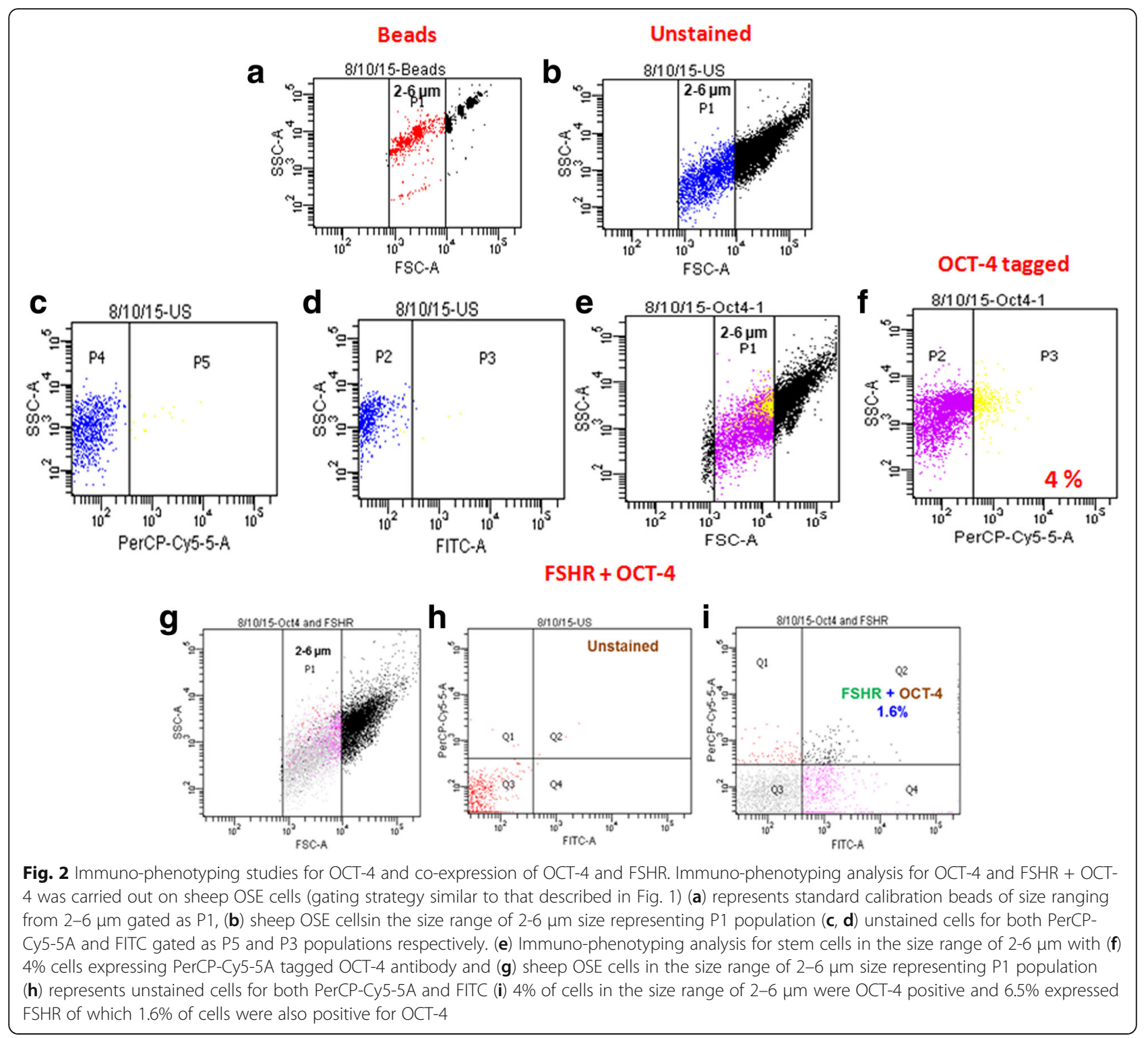

specific oligoprobes has been reported earlier on ovarian stem cells [11]. Similar activation of mouse [34] and human [35] OSCs by FSH has also been reported earlier.

\section{Effect of FSH treatment on sheep ovarian stem cells in vitro}

Different cell types were observed when scraped OSE were observed under a microscope (D0) including large flat epithelial cells and spherical stem cells of two distinct sizes including VSELs and OSCs (Fig. 5a \& b). After $24 \mathrm{~h}$ of culture, epithelial cells became flat, undergo epithelial-mesenchymal transition into fibroblasts and were attached to the bottom of the culture dish (Fig. 5c) whereas spherical stem cells were found singly or in close proximity to the somatic bed in the culture (Fig. 5d). Addition of FSH in the culture medium for $24 \mathrm{~h}$ had a prominent effect on the stem cells which were found to exist in small clusters (Fig. 5e-g) compared to untreated control where the spherical cells were seen singly (Fig. $5 c$ \& d). These clusters of progenitor stem cells result due to incomplete cytokinesis and resemble germ cell nests (Fig. $5 \mathrm{~g}$ ) reported in fetal ovaries and as reported earlier by our group [12]. More number of germ cell clusters were observed after FSH treatment compared to untreated control. Evidently, FSH treatment stimulated the stem cells to undergo proliferation and clonal expansion to form germ cell nests (Fig. 5g) which exist on top of the flattened somatic cells bed (Fig. 5e).

Spherical stem cells present singly or in small clusters expressed OCT-4, VASA and PCNA (Fig. 6a-d) whereas the somatic cells remained distinctly negative. qRT-PCR 


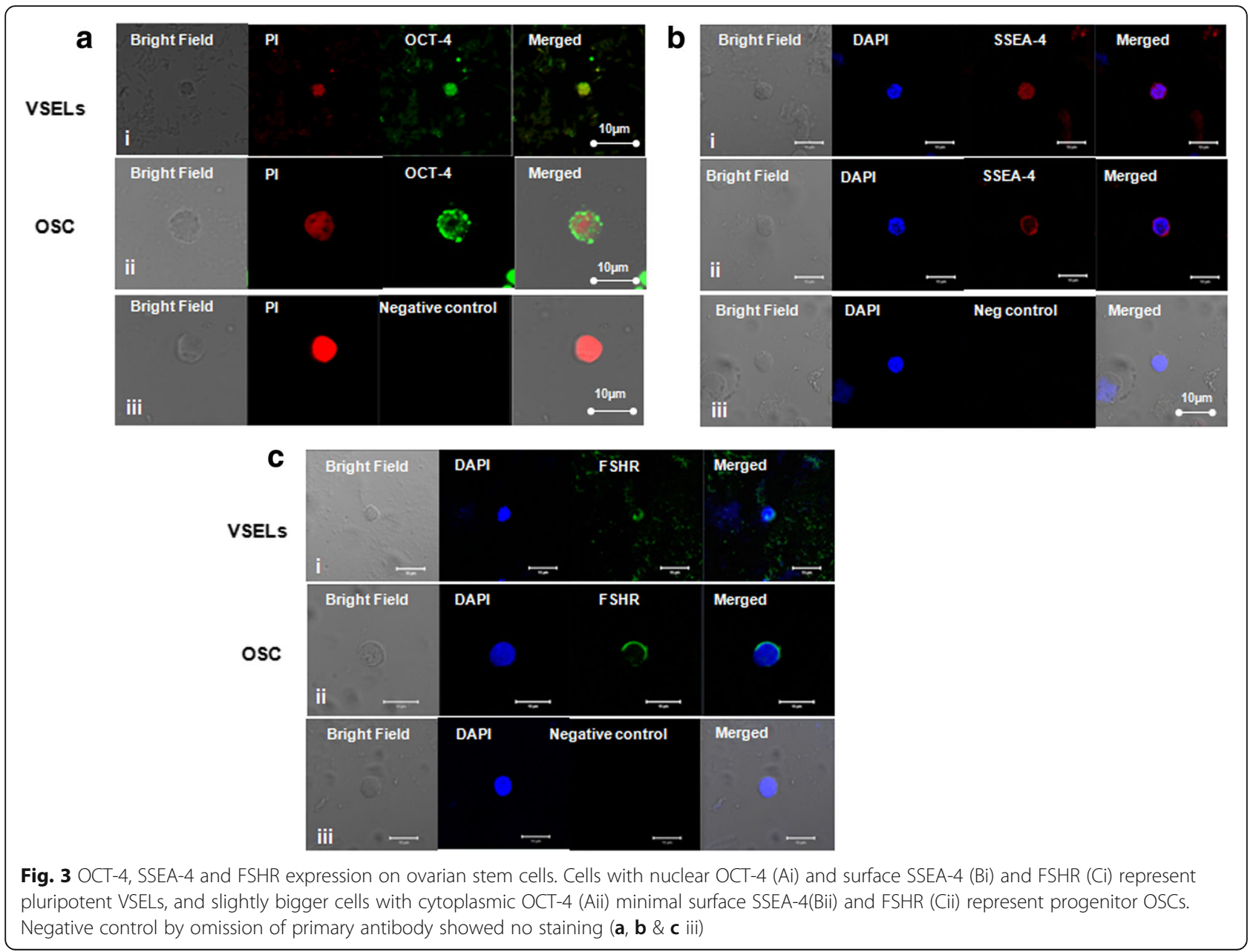

analysis of OSE cells after $24 \mathrm{~h}$ of FSH treatment compared to untreated controls showed an increased expression of stem/germ cell (Oct-4A, Sox-2, Stat-3, Total OCT-4 and Vasa) along with proliferation (Pcna) specific transcripts suggesting a stimulatory effect of FSH on the stem cells (Fig. 6e). Moreover, alternately spliced Fshr3 was markedly up regulated by FSH treatment compared to Fshr1 after 24 h of FSH treatment (Fig. 6f). Further ICC studies confirmed FSHR expression on the stem cells (Fig. 7a-b). Both symmetrical (daughter cells of similar size) and asymmetrical (daughter cells of unequal size) cell divisions were observed after FSH treatment (Fig. 7c) similar to our earlier findings in testis [17] To clearly understand the heterogeneity of ovarian stem cells in OSE, various cells were arranged to understand their hierarchy (Fig. 7c) on the basis of their size. As evident, small VSELs underwent asymmetric cell division to give rise to slightly bigger progenitors OSCs which underwent symmetric cell division and clonal expansion with incomplete cytokinesis to form spheres resembling gem cells nests described in fetal ovaries. Additional file 1: Figure S7 shows different fields that were placed together to make the composite shown in Fig. 7. FSHR expression was also studied by confocal microscopy on cultured OSE cells. VSELs, OSCs and germ cell nest were found to express FSHR (Fig. 7d).

ACD was also characterized by immuno-fluorescence studies. At places, stem cells (VSELs) expressing SSEA-4 were observed to possibly undergo asymmetric stem cell division giving rise to slightly bigger OSCs (Fig. 8Ai and $\mathrm{Ci}$ ) and the dividing cells also co-expressed FSHR and SSEA-4 (Fig. 8b). It was intriguing to observe a small sized VSEL (co-expressing SSEA-4 and FSHR) to undergo asymmetric stem cell division giving rise to slightly bigger OSC (Fig. 8Ci-ii). Co-expression of FSHR and OCT-4 was also observed on dividing doublets (Fig. 9).ACD of VSELs to give rise to the OSCs was further studied by coexpression of OCT-4 and NUMB (Fig. 10).

To conclude from this section, results show that the cells obtained by scraping the ovarian surface include epithelial and stem cells. Epithelial cells (negative for OCT-4 and VASA) undergo epithelial-mesenchymal transition and attach to the culture surface in vitro. Spherical stem cells of two distinct sizes with high nucleo-cytoplasmic 

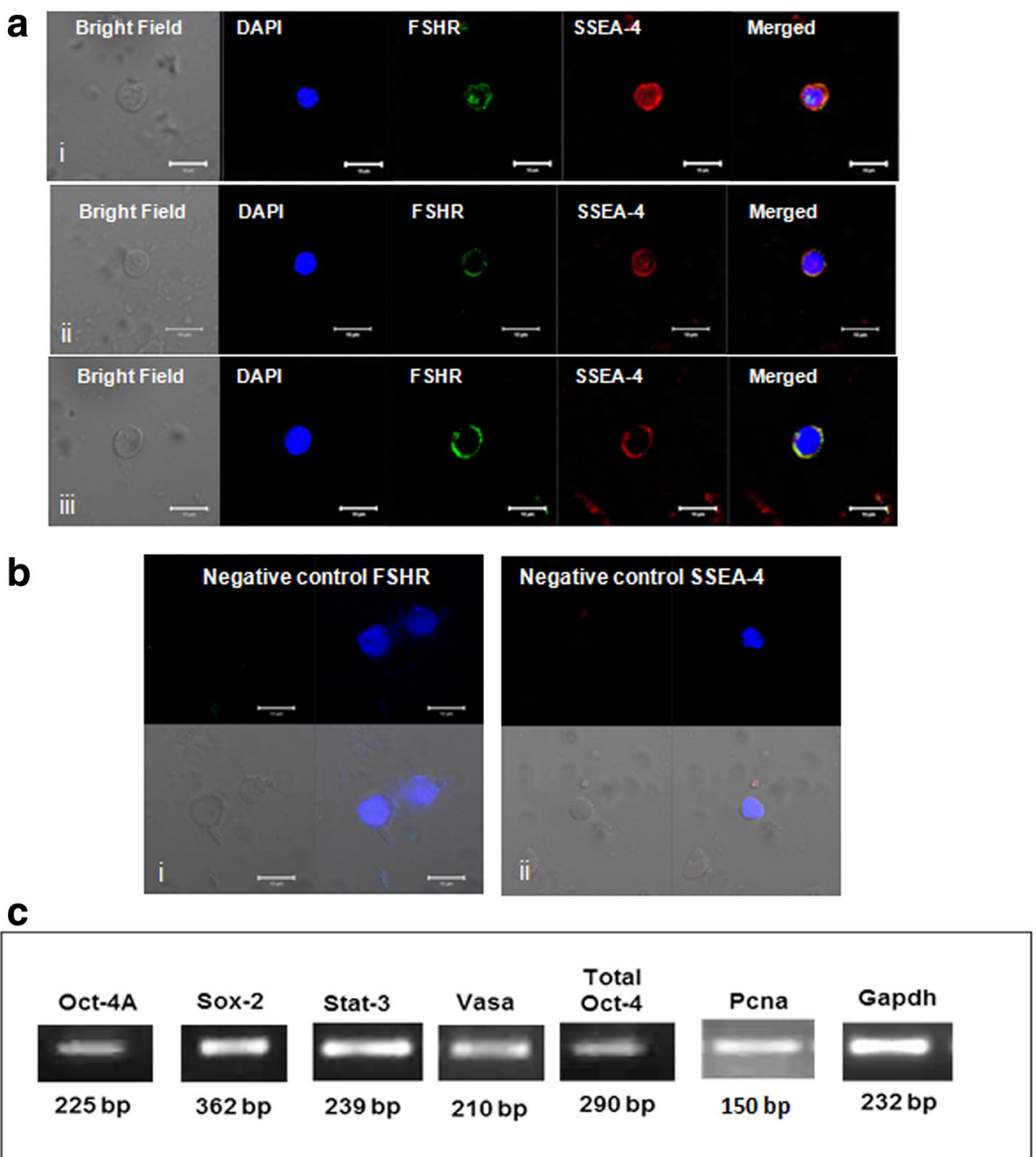

Fig. 4 Co-expression of FSHR and SSEA-4 on ovarian stem cells. a Co-expression of SSEA-4 and FSHR on stem cells (b) Negative control by omission of primary antibody for both FSHR and SSEA-4 (c) RT-PCR results on manually scraped OSE cells showing amplification of pluripotent (Oct-4A, Sox-2, Stat-3), progenitor (Total Oct-4) and germ (Vasa) cells markers along with marker for proliferation (Pcna) and housing keeping gene (Gapdh) at transcript level

ratio are visualized and express OCT-4, VASA, PCNA. SSEA-1 and OCT-4 positive stem cells were found to coexpress FSHR. Overnight culture of the cells in the presence of FSH resulted in increased expression of Fshr1 and Fshr3in agreement with earlier reports [11, 17]. Evidence is also generated to show that VSELs undergo asymmetric cell divisions to give rise to OSCs which undergo symmetric cell divisions and clonal expansion to form spheres similar to our recent reports on testicular [17] and bone marrow [21] stem cells. These dividing cells also showed differential expression of OCT-4 and NUMB.

\section{Histology and PCNA, OCT-4 \& FSHR expression on sheep ovarian sections}

$H \& E$ stained ovarian sections showed prominent, cuboidal, epithelial cells (Fig. 11a) lining the cortical tissue which contained large number of germ cells (Fig. 11b-c). Ovarian cortex comprised oogonial clusters devoid of surrounding granulosa cells (Fig. 11b-c) and primordial follicles surrounded by one to two layers of granulosa cells. Follicles in different stages of development including primary to secondary follicles were also observed surrounded by 2-3 layers of granulosa cells. Interestingly few cells in OSE and cohort of follicles/germ cell nest with incomplete cytokinesis in the cortex were found to express PCNA (Fig. 11d \& e; Additional file 1: Figure S8). Individual oogonial cells in primordial, primary and secondary follicle oocytes were positive for PCNA whereas surrounding granulosa cells were completely negative (Fig. 11g). In contrast, granulosa cells of growing follicles expressed PCNA (Fig. 9h) whereas oocytes revealed faint PCNA expression. 

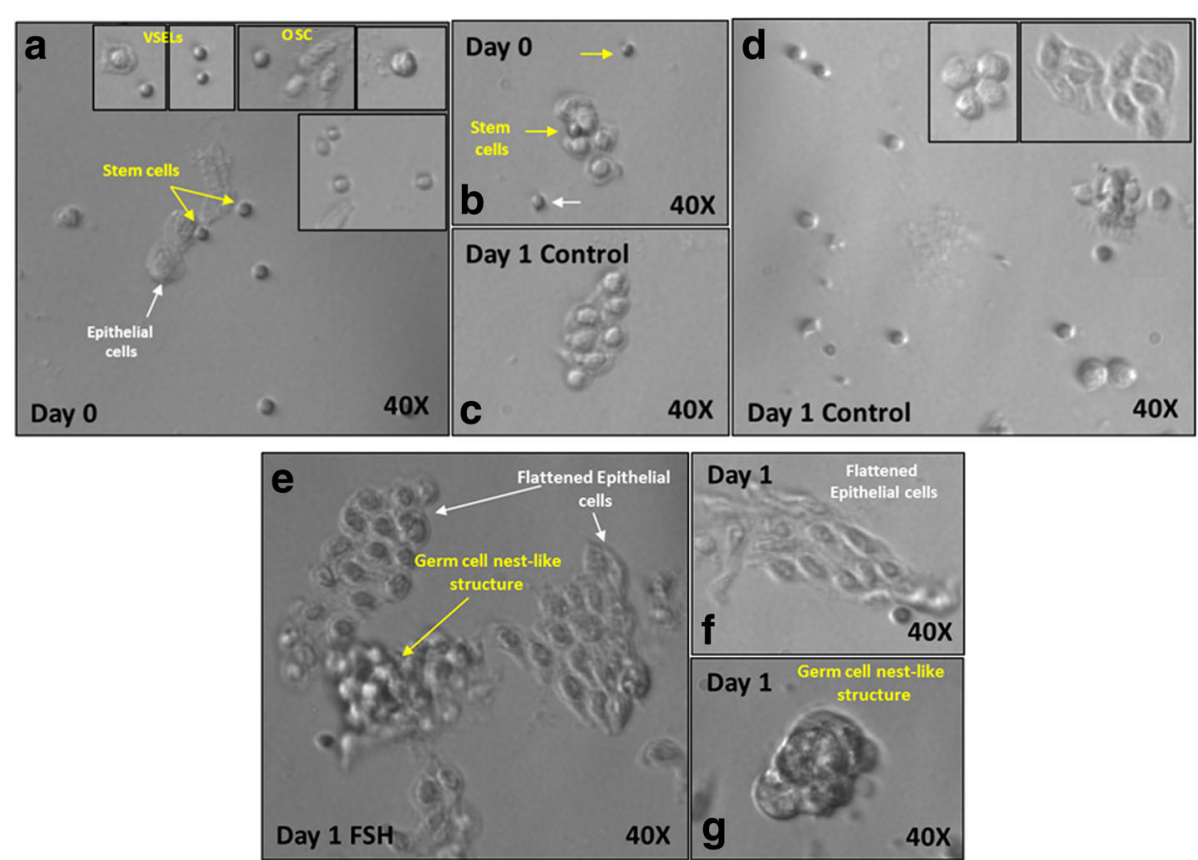

Fig. 5 In vitro culture of manually scraped sheep ovary surface epithelial (OSE) cells in presence of FSH. a-b OSE cells in initial culture show presence of different cell types including large epithelial cells (white arrow), small spherical VSELs and slightly larger OSCs (yellow arrow). Stem cells are observed in close association with large epithelial cells. c-d Untreated (without FSH) OSE cells after $24 \mathrm{~h}$ of culture show minimal effect on stem cells e-g FSH treatment for $24 \mathrm{~h}$ resulted in distinct changes in OSE culture. Spherical stem cells appeared to increase in numbers and formed small spheres in close association with epithelial cells bed. $\mathbf{f}$ Epithelial cells became flat and were attached to bottom of the culture dish. g Cluster of stem cells formed by incomplete cytokinesis (clonal expansion) resembled germ cell nest-like structures
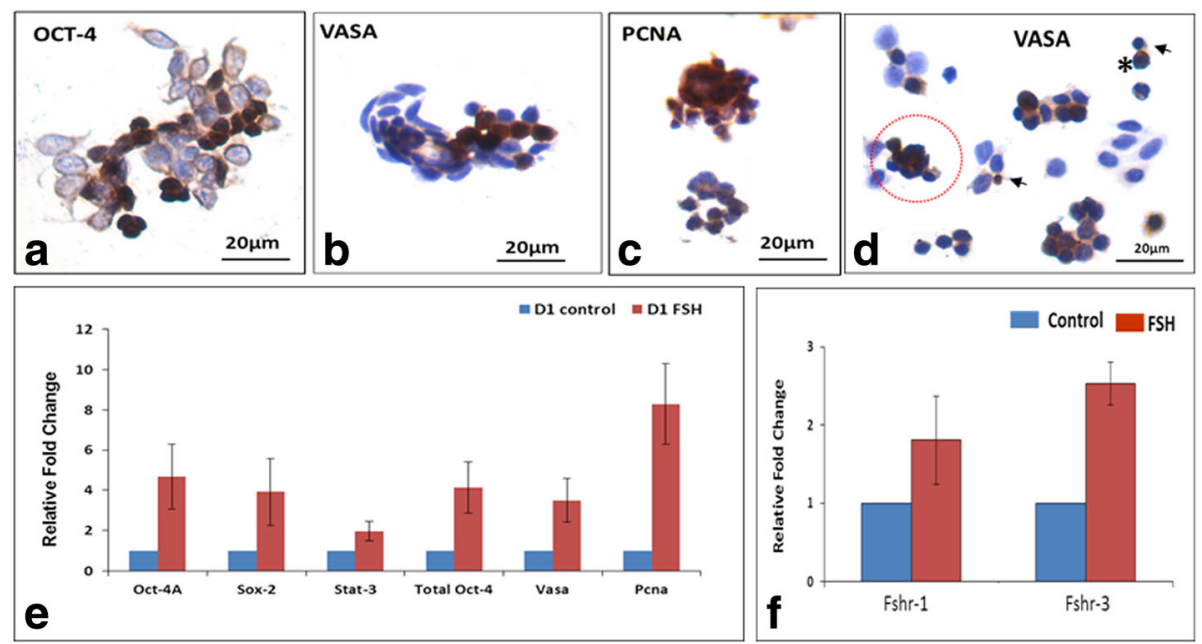

Fig. 6 Characterization of germ cell nest-like structures obtained after FSH treatment. These structures with incomplete cytokinesis were observed to be positive for (a) OCT-4 (b \& d) VASA and (c) PCNA suggesting stem cells proliferation and clonal expansion in response to FSH treatment. Both small VSELs (arrow) and slightly bigger OSCS (asterix), asymmetric cell division and clonal expansion (circled) were clearly visualized. Note that the epithelial cells were distinctly negative for these markers. Similar structures have been earlier reported also with detailed characterization to show that they indeed represent incomplete cytokinesis and not cell aggregates [6, 7]. e GRT-PCR results on OSE cells showed increased expression of VSELs (Oct-4A, Sox-2, Stat-3), OSCs (Oct-4 and Vasa) and proliferation (Pcna) specific transcripts after 24 h of FSH treatment (red bars) compared to untreated controls (blue bars). Results are representative of three different experiments and error bars represent standard error $\mathbf{f}$ Transcript for alternately spliced FSHR isoform, Fshr3 appears to be more up-regulated after FSH treatment compared to the canonical isoform Fshr1 in agreement with earlier results [6, 12] 


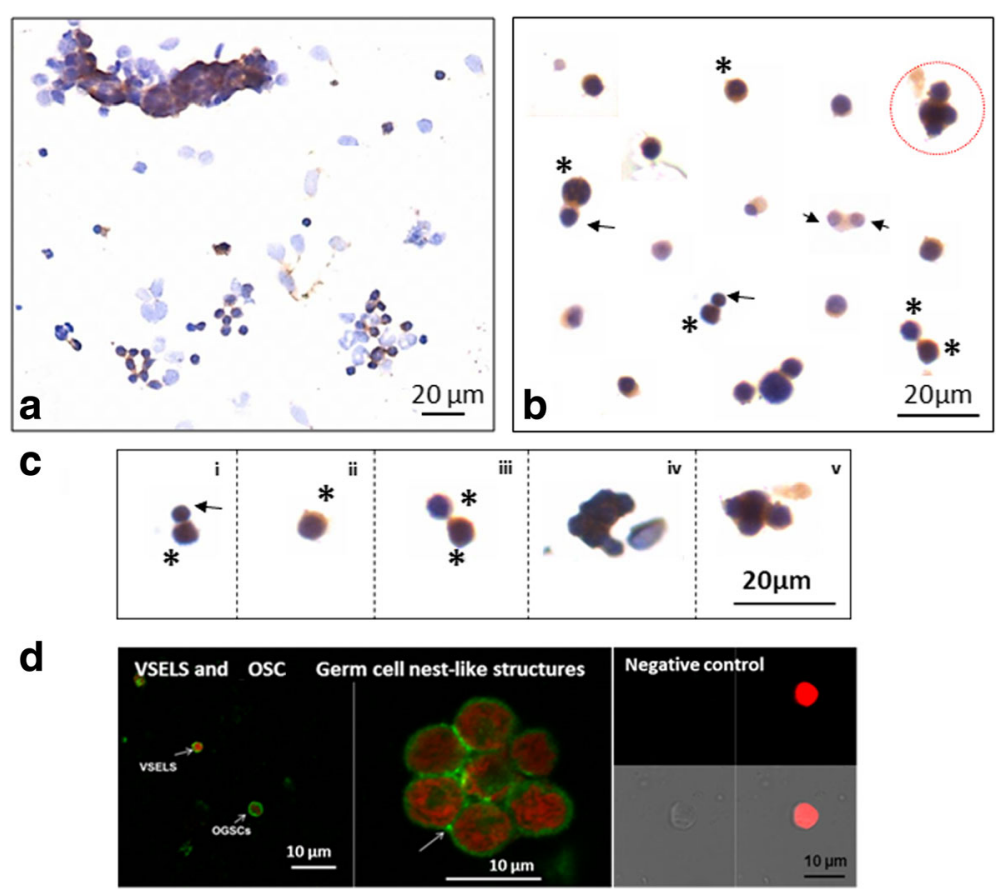

Fig. 7 FSHR expression on cells obtained by scraping sheep ovary surface after FSH treatment in vitro. a Low magnification showing epithelial cells and stem cells in close vicinity with FSHR expression only on the stem cells. $\mathbf{b}$ Various fields were photographed to study stem cells division. Two distinct size of FSHR positive stem cells were visualized including slightly small VSELs (arrow) and bigger OSCs (asterix). Both asymmetric and symmetric cell divisions and germ cell nest-like structures (circled) were clearly visualized. Please note that both (a) and (b) are actually composites prepared by putting together various fields as these cells are spread far apart on the slides. c Stem cells are linearly arranged to understand their biology. (i) Small sized VSEL undergoes asymmetric cell division to give rise to slightly bigger OSCs which (ii) OSC (iii) undergo symmetric cell division (iv-v) and clonal expansion with incomplete cytokinesis to form a germ cell nest-like structure. Similar germ cell nest-like structures in adult ovary have been reported earlier also [6, 7]. d Representative confocal images showing FSHR expression on VSELs/OSCs/germ cell nest-like structure and negative control

Figure 12 shows immuno-localization of OCT-4 (A-G) and FSHR $(\mathrm{H}-\mathrm{R})$ on ovarian sections. Positive staining for OCT-4 was observed in the OSE (A). Oogonial cluster and individual oogonia and oocytes in PF in ovarian cortex along with primary to secondary follicles and cohort of follicles also showed OCT-4 expression (B-D). Initially OCT-4 was observed in the nuclei of oogonia/ oocytes whereas in primary to secondary follicles, OCT4 expression was in the ooplasm and the oocytes were negative (E). Granulosa cells in growing follicles did not express OCT-4. FSHR staining was observed in few cells in OSE along with oogonial cluster and individual oogonia/oocytes including surrounding granulosa cells positive for FSHR. In growing follicles, oocytes and granulosa cells expressed FSHR. Negative controls for this study including peptide blocking of FSHR antibody are provided (Additional file 1: Figure S9).

To conclude from this section, presence of oogonial cluster with incomplete cytokinesis in adult ovary is direct evidence in support of postnatal neo-oogenesis and primordial follicle assembly in ovarian cortex from the ovarian stem cells lodged in the OSE. PCNA expression in OSE cells was not expected if the adult ovary has fixed number of pre-formed primordial follicles at birth however, PCNA expression in stem/progenitor cells in adult ovarian sections in the present study is direct evidence in support of stem cells activity in the adult ovary that may be involved in neo-oogenesis and PF assembly. FSHR expression in growig follicles in the cortical tissue was also intriguing as it is currently understood that FSHR is expressed only on the granulosa cells of growing follicles whereas PF are gonadotropin independent [36]. OCT-4 and FSHR expression in stem cells/oocytes and oogonia in newly assembled follicles suggest that neo-oogenesis and primordial follicle assembly occurs in response to circulatory FSH.

\section{Discussion}

Results of the present study provide additional evidence in support of the presence of two distinct populations of stem cells including pluripotent VSELs and progenitors OSCs localized in the OSE in adult sheep ovary in agreement with our earlier published data [5, 10-14]. VSELs and OSCs are spherical cells with high nucleocytoplasmic ratio and can be distinguished from each other based on their size and OCT-4 expression which is nuclear in VSELs and cytoplasmic in OSCs. Both VSELs and OSCs express FSHR and VSELs undergo ACD to 


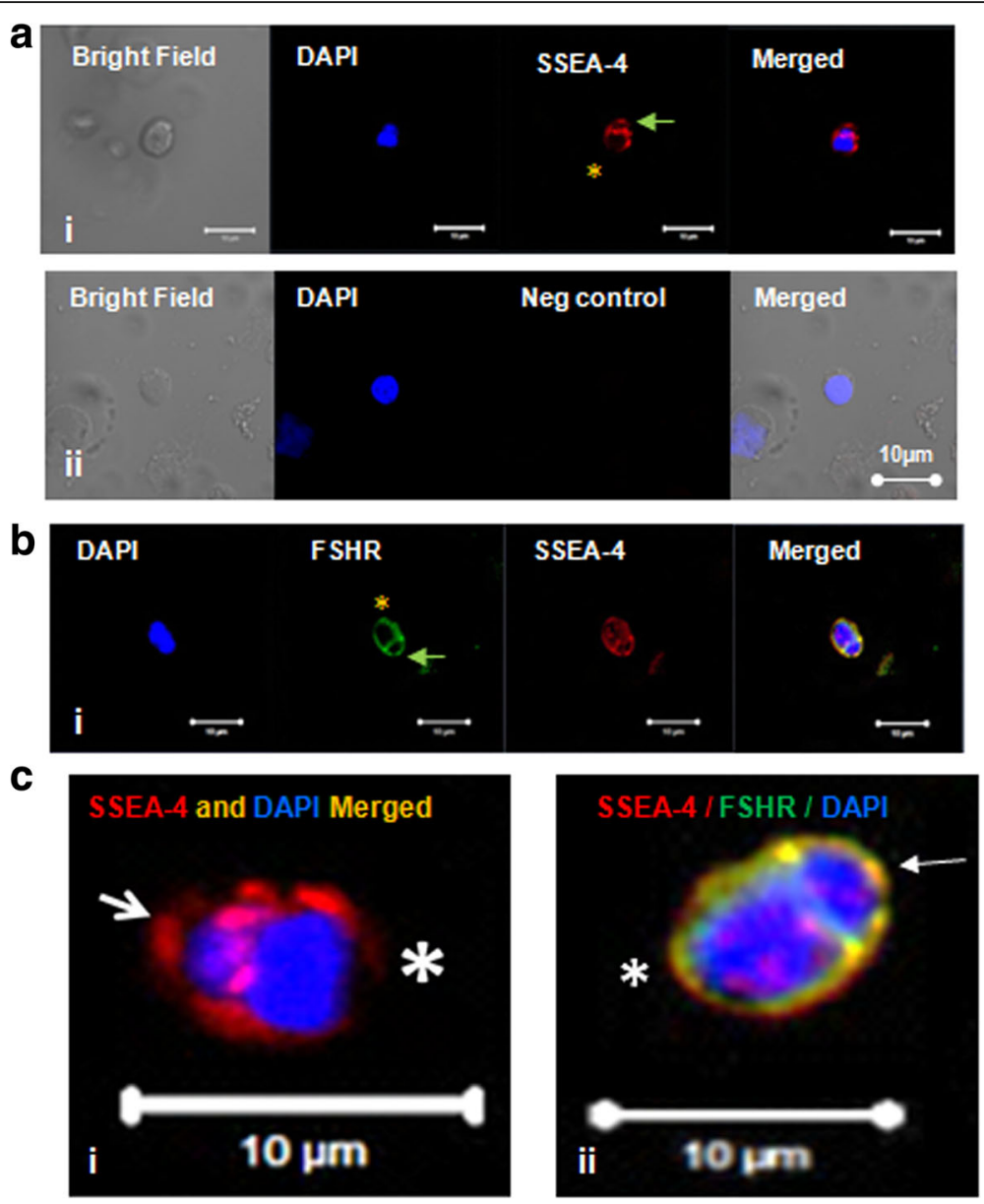

Fig. 8 Expression of SSEA-4 and FSHR on stem cells after overnight exposure to FSH in vitro. (Ai) SSEA-4 and DAPI positive VSEL (green arrow) undergoing asymmetric cell division and give rise to OSC (yellow asterisk). (Bi) Co-expression of FSHR and SSEA-4 on dividing stem cells of different sizes (c) Magnified view of Ai and B

self-renew give rise to OSCs that undergo SCD and clonal expansion to form germ cell nests in response to FSH treatment may be via alternately spliced FSHR3 isoform confirming our earlier data [11]. Expression of FSHR on stem cells (besides granulosa cells) was further confirmed in the present study by different approaches (immuno-phenotyping, IF, RT-PCR). Also pre-incubating FSHR antibody with specific peptide (against which it was raised) during immuno-localization studies completely abrogated FSHR expression thus proving that FSHR expression on the stem cells is specific. Coexpression of pluripotent stem cell markers SSEA-4/ OCT-4 with FSHR on stem cells in OSE cells smears provide additional evidence to support the presence of pluripotent stem cells in OSE that express FSHR. Evidence is also provided for the first time in the literature that most primitive, pluripotent VSELs undergo asymmetric cell division (ACD) to give rise to the OSCs which in turn undergo symmetric cell division and clonal expansion to form a germ cell nest. VSELs and
OSCs are of unequal size, have different fate and show distinct gene expression of OCT-4 and NUMB similar to our earlier results on bone marrow [21] and testis [17]. These results and effect of FSH on ovarian stem cells to give rise to germ cell nests-like structures are in contrast to the findings of Lei and Spradling [37] who failed to detect stem cells activity and germ cell nests in adult ovary. The reasons why they failed to detect stem cells and germ cell nests in adult ovary were discussed [38]. We have earlier reported similar spheres in chemoablated mouse ovary after FSH treatment [12]. Formation of these clusters with cytoplasmic connectivity or 'nests' is not characteristic of only ovarian stem cells but is the property of stem cell derived tissue-specific progenitors and germ cell nests represent sphere formation like mammosphere, cardiosphere, neurosphere etc. before initiating differentiation.

Present study also provides further direct evidence in support of postnatal neo-oogenesis and primordial follicle assembly in adult sheep ovary and that it possibly 


\section{FSHR/OCT4/ DAPI}
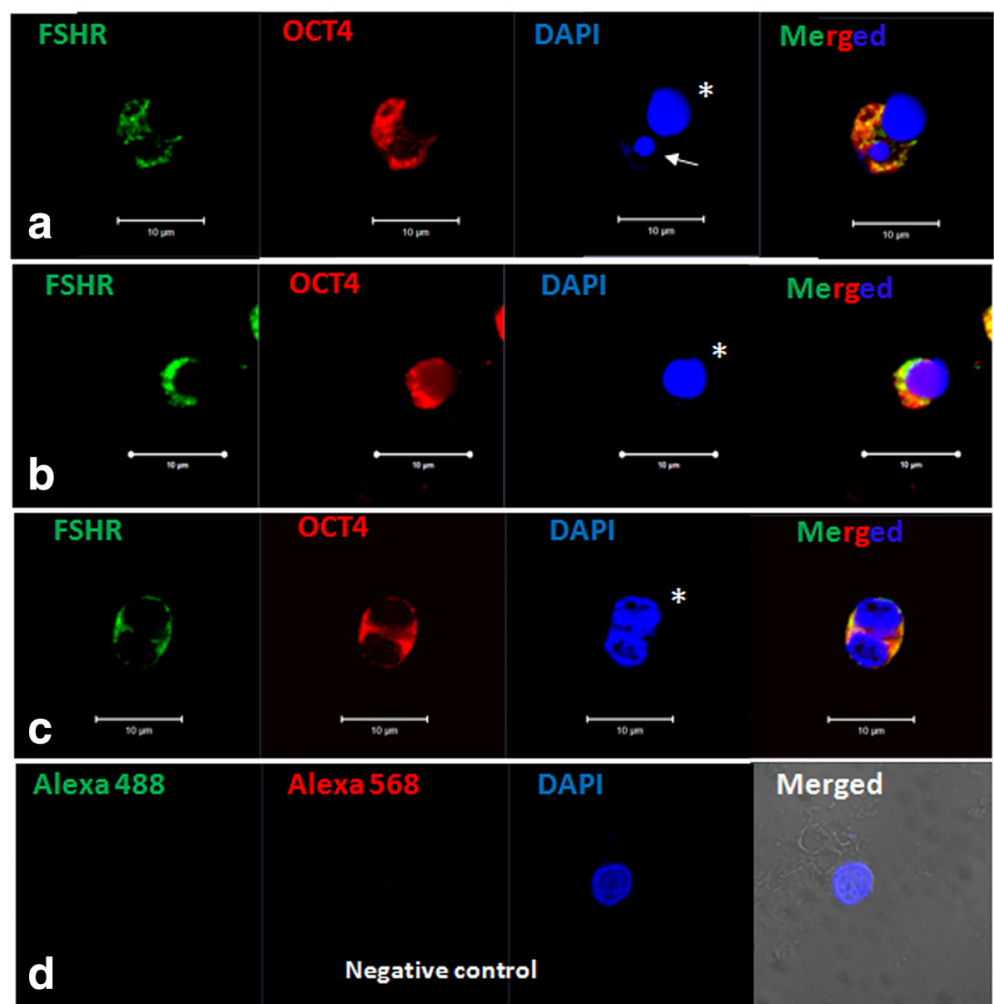

Fig. 9 Co-expression of OCT-4 and FSHR on stem cells after overnight exposure to FSH in vitro. a OCT-4 (Red) and FSHR (green) positive small VSEL (arrow) undergoing asymmetric cell division and give rise to large progenitor OSC (asterisk). b Co-expressing FSHR and OCT-4 positive ovarian stem cells (c) Co-expression of FSHR and OCT-4 on dividing stem cells of same sizes representing symmetric cell division. $\mathbf{d}$ Negative control by omission of primary antibody showed no staining. Scale bar $10 \mu \mathrm{m}$

occurs in response to FSH. If the ovary is endowed with a fixed number of primordial follicles at birth, one would not expect to observe PCNA expression in oogonia/oocytes in the ovarian cortex of adult sheep ovary. On the contrary, we observed PCNA expression in oogonia/oocytes in primordial follicles in the ovarian cortex. In addition, a distinct staining for OCT-4 and FSHR along with PCNA was also observed on the stem cells lodged in the OSE which differentiate into oogonia/oocytes. OCT-4 positive stem cells in OSE may proliferate in response to FSH and undergo clonal expansion to form 'spheres' or 'nests', meiosis, GCN breakdown and PF assembly in adult sheep ovaries. We have earlier reported similar activity of stem cells in adult mouse OSE/ovarian cortex on treatment with PMSG [34].

Similar to various stages described in fetal ovary [39, 40], we have shown that adult ovarian cortex harbor germ cell nests comprising of a cluster of oogonia with continuous cytoplasm and surrounded by a single layer of granulosa cells. Germ cell nest breaks down and the surrounding somatic cells surround the oocytes to assemble as individual primordial follicles. That the cells in the nest arise from the stem cells was confirmed (i) by in vitro study wherein FSH treatment stimulated the stem cells to undergo asymmetric/symmetric cell divisions and clonal expansion and (ii) by expression of PCNA/OCT-4/FSHR on stem cells and the differentiated oogonia in ovarian sections.

Thus besides the currently held view that FSH acts on the granulosa cells in the ovary and on Sertoli cells in the testis, FSH receptors are also expressed on the stem cells (VSELs, OSCs/SSCs) in the gonads and FSH exerts a direct action resulting in their proliferation $[11,17]$. It is widely accepted that FSH exerts its action on the granulosa cells of growing pre-antral follicle whereas initial follicle growth is gonadotropin independent. However, emerging direct action of FSH on stem cells (which also express FSHR) is indeed intriguing. Also the VSELs and HSCs in the hematopoietic system also express FSH and sex hormone receptors [25-28]. Presence of FSHR on granulosa cells alone in the ovary cannot explain FSHR expression on ovarian cancer cells whereas FSHR expression on the stem cells in the OSE can explain why more than $90 \%$ of ovarian cancers express FSHR and arise from the epithelial cells lining the ovary and fimbriae epithelium. Auresperg has earlier reported that 


\section{Numb /OCT4/ DAPI}

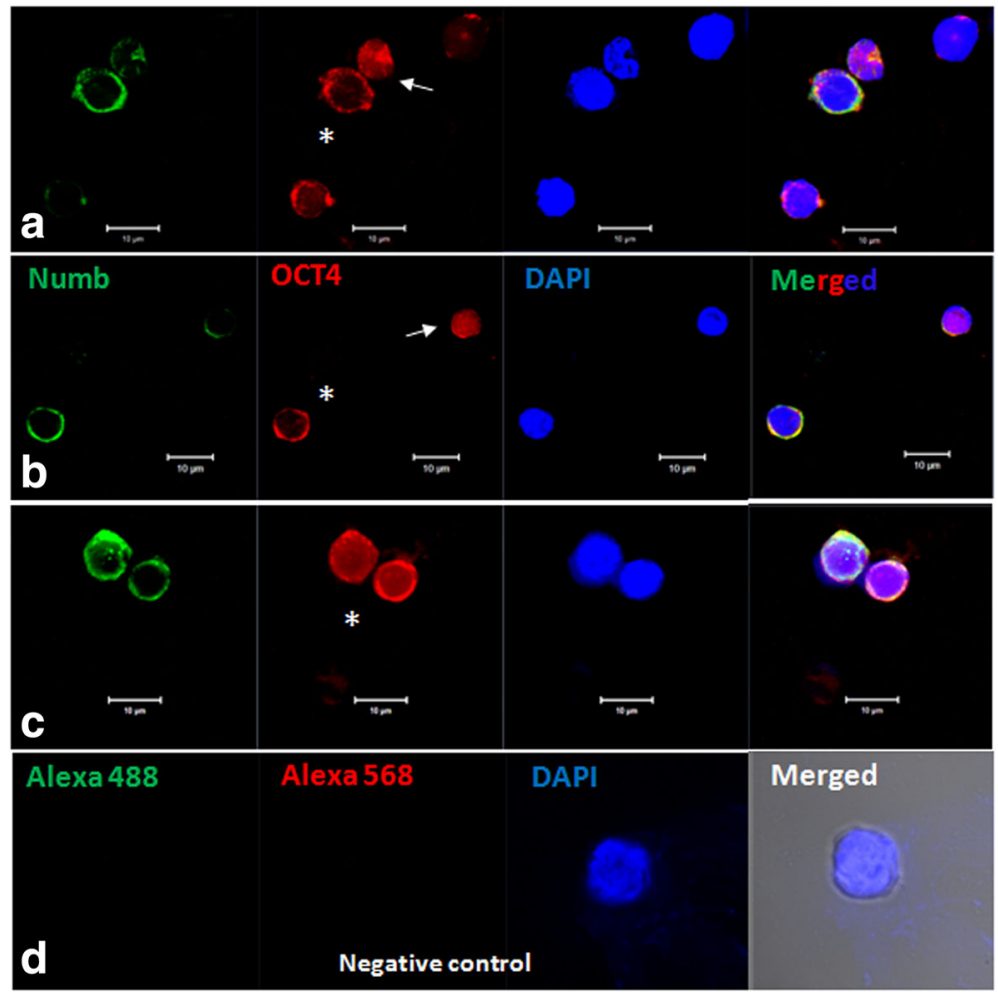

Fig. 10 Co-expression of NUMB and OCT-4 on dividing ovarian stem cells a Nuclear OCT-4A positive VSEL (arrow) undergoing asymmetric cell division (ACD) to give rise to OSC (asterisk). $\mathbf{b}$ Co-expression of OCT-4A and NUMB on different sizes of stem cells shown different expression pattern for (NUMB an OCT-4A). Please note that smaller stem cells express nuclear OCT-4A (red) with minimal expression of NUMB. Whereas slightly bigger progenitor cell show OCT-4A expression in cytoplasm but not in nucleus with clear uniform distinct expression pattern for NUMB (green) in cytoplasm. c Co-expression of NUMB and OCT-4 on progenitor ovarian stem cells undergoing symmetric cell division (SCD). Please note progenitor cells are of equal sizes and expresses similar expression pattern for (NUMB and cytoplasmic OCT-4A). $\mathbf{d}$ Negative control by omission of primary antibody showed no staining. Cells were counterstained with DAPI. OCT-4A is a nuclear transcription factor suggesting pluripotent state whereas NUMB is expressed by, progenitor OSC and is implicated to suppress Notch signaling essential for maintaining undifferentiated stem cells. Scale bar $10 \mu \mathrm{m}$

stem cell profile of OSE is reproduced in the oviductal fimbriae [41]. Ovarian cancers possibly arise from stem cells which express FSHR and are located in the OSE [42] and this was recently confirmed by Virant-Klun's group [43].

A careful review of literature reveals that primers selection for RT-PCR and in situ hybridization from different exons of FSHR gene and presence of alternatively spliced FSHR isoforms led to the erroneous conclusion that initial follicle growth is gonadotropin independent. Earlier studies in late nineties in sheep [44] and humans [45] used techniques like in situ hybridization and RT-PCR to study FSHR expression on ovarian follicles of different stages of development. FSHR mRNA was observed only in growing follicle in both sheep and humans and not in the early primordial follicles [44, 45]. In contrast, other groups reported FSHR on OSE $[46,47]$ and on oocytes $[48,49]$ and also on carcinoma cells [50-52]. Interestingly Zheng et al. [46] used primer sequences from exons 1-5 (which are common in both FSHR1 and FSHR3) of FSHR gene to demonstrate FSHR in the OSE. Meduri et al. [53] showed FSHR (not LHR) binding to human oocytes of primary follicles at both protein and mRNA level (20 folds more than on granulosa cells). FSH binding to oocytes was shown by autoradiography, oocytes responded by mobilization of $\mathrm{Ca} 2+$ and authors suggested a direct action of FSH on oocytes development. They used anti FSHR antibody raised against the extracellular domain of FSHR and a 366 bp FSHR transcript (using primers from exons 7 and 10) was detected in granulosa cells whereas a 191 bp product against FSHR (using primers from exons 2 and 4) was detected in the oocytes.

Thus it is very evident that alternatively spliced FSHR transcripts are involved in FSH action and both Oktay [45] and Tisdall [44] studies missed out on FSHR expression in primordial follicles since they used primers spanning exons 8-10 for RT-PCR and in situ hybridization which are specific to G-protein coupled, 


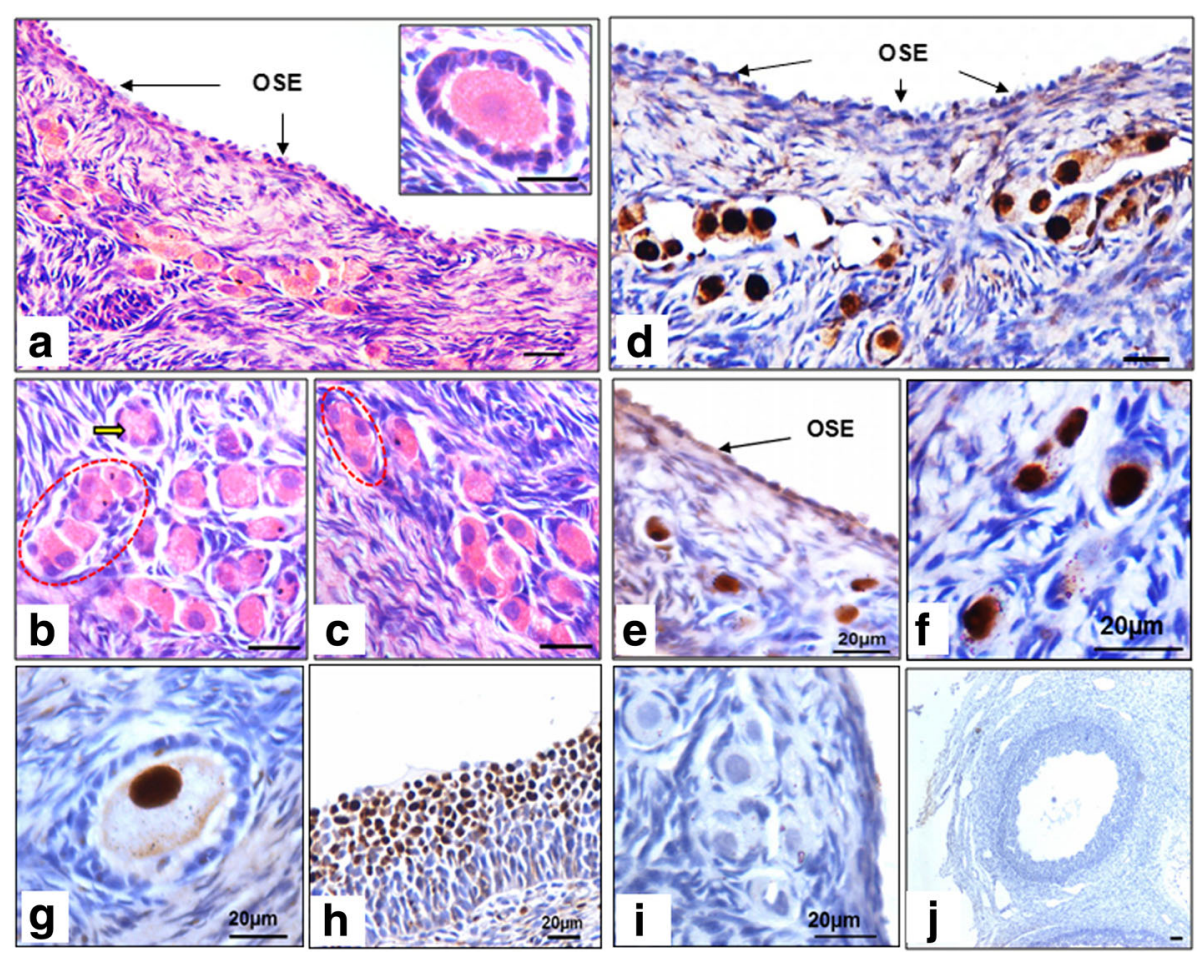

Fig. 11 PCNA immuno-localization on sheep ovarian sections. H\&E staining of ovarian sections (a) shows a distinct layer of OSE cells (b-c) cohort of cytoplasmically connected oocytes i.e. a germ cell nest surrounded by few pre-granulosa cells. These structures are referred to as ovigerous cords in literature (Smith et al. 2014). Few primordial and primary follicles were located in the cortical region whereas large oocytes were present in medulla region. $\mathbf{d}$-h Immuno-localization with PCNA showed few OSE cells positive for PCNA, cluster of oocytes/germ cell cyst, individual primordial and primary follicles located in cortical region of ovary showed strong nuclear PCNA. Interestingly surrounding granulosa cells and stromal cells were completely negative for PCNA. Large Graffian follicle in medulla region showed weak PCNA expression in both nucleus and ooplasm of oocytes however, (h) surrounding granulosa cells were strongly positive for PCNA. i \& j Negative control

canonical FSHR1 receptor and are spliced out in alternatively spliced growth factor type 1 FSHR3 receptor [24]. This is the reason why these groups did not detect FSHR on PF in contrast to studies by Zheng [46] and Meduri [53] discussed above. FSH-R3 signaling pathway includes cAMP-independent activation of ERK downstream of an SNX-482 sensitive component likely to be the Cav2.3 calcium channel. Using sheep ovaries, Sullivan et al. [54] reported that Fshr3 is the predominant transcript in small, medium and pre-ovulatory follicles and not the canonical Fshr1. Similarly, Babu et al. [55] reported that PMSG treatment to 21 days old mouse induced higher up-regulation of Fshr3 compared to Fshr1 and a band of $39 \mathrm{kDa}$ was detected using an antibody specific to Fshr3 by Western blotting (in contrast to $78 \mathrm{kDa}$ band generally expected for canonical FSHR1). Our results demonstrate that in both testes [17] and ovaries [11], FSH exerts its action on the stem/germ cells via alternatively spliced Fshr3 receptor which gets more up-regulation compared to Fshr1. Using the same FSHR antibody raised against exon 2 which is conserved in alternately spliced isoforms, we recently detected all the 4 FSHR isoforms in mouse uterus [56].
Several groups [57-59] in the past have reported effect of FSH treatment on OSE. FSH was also demonstrated to be involved during PF formation in hamster ovary [60]. We have also reported that numbers of PF cohorts in the ovarian cortex are increased after PMSG treatment [34]. This was associated with an increase in pluripotent transcripts (Oct-4A, Nanog), meiosis (Scp-3) and germ cells (Oct-4B, Mvh) specific markers. MVH showed positive immuno-staining on germ cell nest-like clusters and at places primordial follicles appeared connected through oocytes/oogonia. The stem cells are activated in response to FSH treatment and also undergo meiosis. These results were supported by studies undertaken in vitro wherein human and marmoset cortical tissue was cultured in presence and absence of FSH [35]. Large numbers of ovarian stem cells were released on the cell culture insert and could spontaneously differentiate into oocytes-like structures [61]. qRT-PCR analysis revealed that treating cortical tissue pieces with FSH $(0.5 \mathrm{IU} / \mathrm{ml})$ or $\mathrm{bFGF}(100 \mathrm{ng} / \mathrm{ml})$ for 3 days resulted in an increased expression of gene transcripts specific for VSELs (Oct-4A, Nanog), OSCs(Oct-4), early germ cell (c-Kit, Vasa) and PF growth initiation (oocytes-specific 
(1) OCT-4

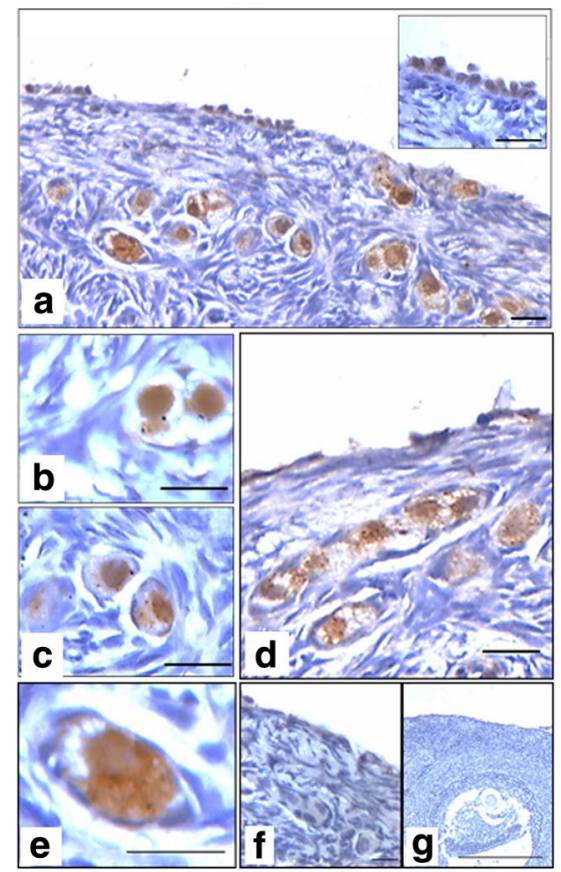

(2) FSHR

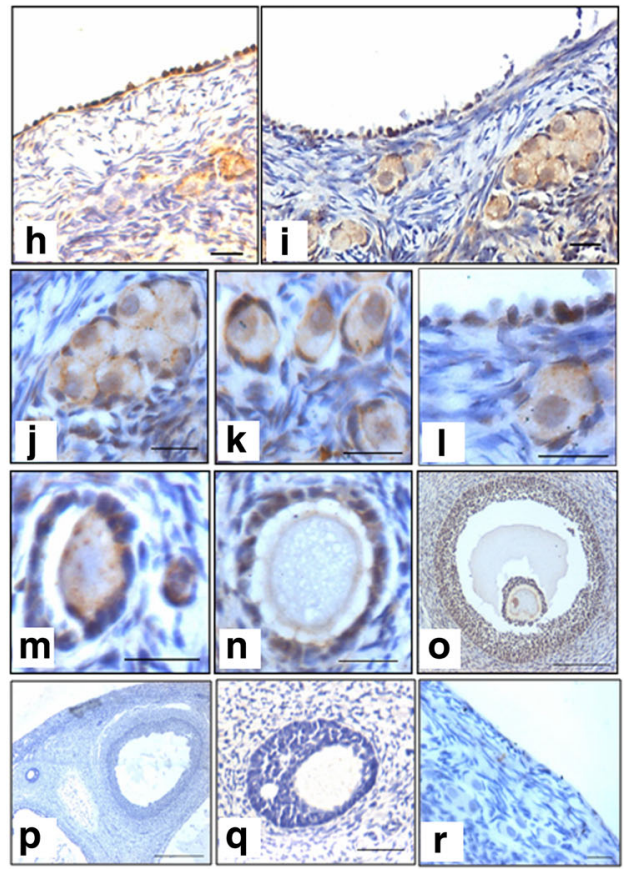

Fig. 12 OCT-4 and FSHR immuno-localization on sheep ovarian sections. a Few cells on OSE were positive for OCT-4 (b-d) cluster of oocytes/oogonia in primordial and primary follicles and ooplasm were positive for OCT-4 whereas (c-e) surrounding granulosa cells and stromal cells were completely negative. Oocytes in large secondary and tertiary follicles in medulla region also showed OCT-4 expression whereas surrounding granulosa cells were negative. $\mathbf{f}-\mathbf{g}$ Negative control with omission of primary antibody. h-i OSE cells show FSHR expression, (j) cluster of oocytes, (k-m) individual primordial and primary follicles oocytes nucleus and ooplasm both were positive for FSHR including surrounding granulosa cells, stromal cells were completely negative. $\mathbf{n}$-o In medulla region larger oocytes \& ooplasm including surrounding granulosa cells were positive for FSHR. p Negative control with omission of primary antibody (q-r) Negative control using peptide blocking of antibody

Gdf9, Lhx8 and granulosa cells specific Amh) suggestive of follicular transition [35]. Also Parte et al. [61] showed the presence of germ cell nests, Balbiani body-like structures and cytoplasmic streaming extensively described during fetal ovary development, are indeed well recapitulated during in vitro oogenesis in adult OSE cultures.

Several lines of evidence exist to support our results suggesting a unique role of FSH during PF formation. A closer examination of FSHR knockout ovary shows significant reduction in pool of primordial and primary follicle compared to normal mice ovary follicle count [62, 63]. Possibly certain compensatory mechanisms or altered cell signaling pathways may be functional and result in PF assembly. O'Shaughnessy et al. [64] have reported that FSHR mRNA and alternate splicing is detectable in day 1 ovaries (with only PF) and increase further on Day 5 (when primary follicles first appear). In hypogonadal (hpg) mice which lack circulating gonadotropins show normal levels of FSHR mRNA up to D15 suggesting the existence of compensatory mechanisms for FSH actin. Allan et al. [65] have reported that FSH treatment to mature hpg mice increases the primordial follicles reserve. Roy and Albee [60] reported that FSH is crucial for PF formation in hamster ovaries as well. Injecting
FSH-specific polyclonal antibody in pregnant hamsters resulted in dramatic loss of PF and this effect was reversed by treatment with FSH analog (PMSG). Lei et al. [66] reported that in mouse ovaries (postnatal days 1-3),

FSH facilitates germ cell nest breakdown and PF formation. Results of present study are stimulating but at the same time still in a preliminary stage. It will be a challenge to demonstrate neo-oogenesis and follicular assembly in adult ovary in vivo and newer models need to be developed to detect the same. A recent study [67] has demonstrated that transplanted female germ line stem cells can restore function of POF ovary and generate offspring. Our results suggests that similar to testicular stem cells [15], ovarian VSELs also undergo asymmetric cell divisions (ACD) whereas OSCs undergo symmetric cell divisions (SCD) and clonal expansion to form germ cell nests. Expression of FSHR on stem cells and the possibility that FSH may exert a direct action on ovarian stem cells leading to neooogenesis and follicle assembly provides a paradigm shift in our current understanding of FSH action on ovaries.

\section{Conclusions}

To conclude, adult ovary harbors two distinct populations of stem cells including VSELs and OSCs in the 
OSE and is as dynamic in nature as the testis producing gametes throughout life rather than harboring fixed pool of gonadotropin independent primordial follicles. We show for the first time, that VSELs are the most primitive pluripotent stem cells with nuclear OCT-4 that selfrenew and give rise to slightly bigger OSCs with cytoplasmic OCT-4 by undergoing ACD. These OSCs in turn undergo SCD and clonal expansion to form GCN. GCN breakdown and undergo further differentiation into oocytes and PF assembly. The stem cells express FSHR and respond directly to FSH. The existing concept that initial PF growth is gonadotropin independent is possibly incorrect and this confusion occurred due to presence of FSHR isoforms which requires careful primer designing for RT-PCR studies. Also data is generated how the stem cells possibly act under normal physiological conditions to form PF. The study provides huge scope for further research on the involvement of stem cells during neo-oogenesis and PF assembly in adult ovary and also provides novel understanding leading to menopause and cancer and novel targets for fertility regulation.

\section{Additional file}

Additional file 1: Figure S1. The presence of two stem cell population in OSE by flow cytometry analysis is shown. Table S1. List of antibodies used in the study. Table S2. List of primers used in the study. Figure S2. H \& E staining of freshly isolated sheep OSE smears (arrows represent small putative VSELs smaller then RBCs and asterisk represent OSCs and cell doublets (circled) show dividing stem cells). Figure S3. RT-PCR on freshly isolated OSE cells and granulosa cells surrounding oocytes. Figure S4. FSHR expression on ovarian stem cells. Figure $\mathbf{S 5}$. $\mathbf{Z}$ stack of OCT-4 expressing germ cell clusters in FSH treated OSE cell culture. Figure S5b. Z stack of FSHR expressing germ cell clusters in FSH treated OSE cell culture. Figure S6. Co-expression of FSHR and SSEA-4 on ovarian stem cells. Figure S7. FSHR expression on proliferating and dividing ovarian stem cells cultured in vitro within OSE cells on FSH treatment. Figure S8. H\&E staining of ovarian sections (A) shows a distinct layer of OSE cells (B-C) PCNA immuno-localization on sheep ovarian sections showed few cells in OSE positive for PCNA, cluster of oocytes/germ cell cyst, individual primordial and primary follicles located in cortical region of ovary showed strong nuclear PCNA with faint stain in ooplasm. Figure S9a. Negative control for ICC to show specificity of staining (i) Negative for VASA (ii) Negative for SSEA-4 and PCNA (iii) Negative for FSHR and OCT-4. Figure S9b. Negative control by peptide blocking of FSHR antibody to show specificity of staining obtained using FSHR. (PDF $1911 \mathrm{~kb}$ )

\section{Abbreviations}

ACD: asymmetric cell division; FSH: follicle stimulating hormone; FSHR: FSH receptors; GCN: germ cell nest; HSCs: hematopoietic stem cells; OSCs: ovary stem cells; OSE: ovary surface epithelium; PF: primordial follicles; SCD: symmetric cell division; SSCs: spermatogonial stem cells; VSELs: very small embryonic-like stem cells

\section{Acknowledgements}

The authors thank Shobha and Reshma with their help for confocal microscopy studies and Gayatri and Sushma for their help in carrying out flow cytometry studies.
Funding

Study was funded by core support provided by Indian Council of Medical Research, Government of India, New Delhi to the Institute.

\section{Availability of data and materials}

All the data is provided in the manuscript and the Supplement submitted as a separate attachment.

\section{Authors' contributions}

HP carried out all the experiments, data interpretation and preparation of the manuscript. SP provided technical help to HP. DB helped with study design, data interpretation and manuscript preparation. All authors read and approved the final manuscript.

\section{Ethics approval}

The study is focused on sheep ovaries obtained from the slaughter house after approval from Institute stem cells (ICSCR) and animal ethics (IAEC) committees.

\section{Consent for publication}

This has been obtained from the Institute (RA/455/01-2017).

\section{Competing interests}

The authors declare that they have no competing interests.

\section{Publisher's Note}

Springer Nature remains neutral with regard to jurisdictional claims in published maps and institutional affiliations.

Received: 21 July 2017 Accepted: 26 December 2017 Published online: 05 January 2018

\section{References}

1. Albertini DF, Telfer EE. Deconstructing the winding path to the recapitulation of mammalian oogenesis ex vivo. Proc Natl Acad Sci U S A. 2016:113:9956-7.

2. Woods DC, Tilly JL. An evolutionary perspective on adult female germline stem cell function from flies to humans. Semin Reprod Med. 2013;31(1):24-32.

3. Bhartiya D. Letter to editor: rejuvenate eggs or regenerate ovary? Mol Cell Endocrinol. 2017:446:111-3.

4. Horan CJ, Williams SA. Oocyte stem cells: fact or fantasy? Reproduction. 2017; https://doi.org/10.1530/REP-17-0008.

5. Bhartiya D, Patel H. Ovarian stem cells- resolving controversies. J Assist Reprod Genet. 2017; https://doi.org/10.1007/s10815-017-1080-6.

6. Truman AM, Tilly JL, Woods DC. Ovarian regeneration: the potential for stem cell contribution in the postnatal ovary to sustained endocrine function. Mol Cell Endocrinol. 2017:445:74-84.

7. White YA, Woods DC, Takai Y, Ishihara O, Seki H, Tilly JL. Oocyte formation by mitotically-active germ cells purified from ovaries of reproductive age women. Nat Med. 2012;18:413-21.

8. Virant-Klun I. Postnatal oogenesis in humans: a review of recent findings. Stem Cells Cloning. 2015;8:49-60.

9. Virant-Klun I, Stimpfel M, Cvjeticanin B, Vrtacnik-Bokal E, Skutella T. Small SSEA-4-positive cells from human ovarian cell cultures: related to embryonic stem cells and germinal lineage? J Ovarian Res. 2013;6:24-43.

10. Parte S, Bhartiya D, Telang J, Daithankar V, Salvi V, Zaveri K, Hinduja I. Detection, characterization, and spontaneous differentiation in vitro of very small embryonic-like putative stem cells in adult mammalian ovary. Stem Cells Dev. 2011;20:1451-64

11. Patel H, Bhartiya D, Parte S, Gunjal P, Yedurkar S, Bhatt M. Follicle stimulating hormone modulates ovarian stem cells through alternately spliced receptor variant FSH-R3. J Ovarian Res. 2013;6:52-67.

12. Sriraman K, Bhartiya D, Anand S, Bhutda S. Mouse ovarian very small embryonic-like stem cells resist chemotherapy and retain ability to initiate oocyte-specific differentiation. Reprod Sci. 2015;22:884-903.

13. Bhartiya D. Ovarian stem cells are always accompanied by very small embryonic-like stem cells in adult mammalian ovary. J Ovarian Res. 2015;8:70-3.

14. Parte S, Patel H, Sriraman K, Bhartiya D. Isolation and characterization of stem cells in the adult mammalian ovary. Methods Mol Biol. 2015;1235:203-29. 
15. Bhartiya D, Kasiviswanathan S, Unni SK, Pethe P, Dhabalia JV, Patwardhan S, Tongaonkar HB. Newer insights into premeiotic development of germ cells in adult human testis using Oct-4 as a stem cell marker. J Histochem Cytochem. 2010;58:1093-106.

16. Anand S, Bhartiya D, Sriraman K, Patel H, Manjramkar D. Very small embryonic-like stem cells survive and restore spermatogenesis after busulphan treatment in mouse testis. J Stem Cell Res Ther. 2014;4:216-32.

17. Patel $H$, Bhartiya D. Testicular stem cells express follicle-stimulating hormone receptors and are directly modulated by FSH. Reprod Sci. 2016;23:1493-508.

18. Anand S, Bhartiya D, Sriraman K, Mallick A. Underlying mechanisms that restore spermatogenesis on transplanting healthy niche cells in busulphan treated mouse testis. Stem Cell Rev. 2016;12:682-97.

19. Bhartiya D, Shaikh A, Anand S, Patel H, Kapoor S, Sriraman K, Parte S, Unni S. Endogenous, very small embryonic-like stem cells: critical review, therapeutic potential and a look ahead. Hum Reprod Update. 2016:23:41-76.

20. Ratajczak MZ, Ratajczak J, Suszynska M, Miller DM, Kucia M, Shin DM. A novel view of the adult stem cell compartment from the perspective of a quiescent population of very small embryonic-like stem cells. Circ Res. 2017;120:166-78.

21. Ganguly R, Metkari S, Bhartiya D. Dynamics of bone marrow VSELs and HSCs in response to treatment with gonadotropin and steroid hormones, during pregnancy and evidence to support their asymmetric/symmetric cell divisions. Stem Cells Rev Rep. 2017; https://doi.org/10.1007/s12015-017-9781-x.

22. Siegel ET, Kim HG, Nishimoto HK, Layman LC. The molecular basis of impaired follicle-stimulating hormone action: evidence from human mutations and mouse models. Reprod Sci. 2013;20:211-33.

23. Kumar TR. Extragonadal FSH receptor: is it real? Biol Reprod. 2014;91:1-4

24. Sairam MR, Babu PS. The tale of follitropin receptor diversity: a recipe for fine tuning gonadal responses? Mol Cell Endocrinol. 2007;260-262:163-71.

25. Mierzejewska K, Borkowska S, Suszynska E, Suszynska M, Poniewierska-Baran A, Maj M, Pedziwiatr D, Adamiak M, Abdel-Latif A, Kakar SS, Ratajczak J, Kucia M, Ratajczak MZ. Hematopoietic stem/progenitor cells express several functional sex hormone receptors-novel evidence for a potential developmental link between hematopoiesis and primordial germ cells. Stem Cells Dev. 2015;24:927-37.

26. Abdelbaset-Ismail A, Suszynska M, Borkowska S, Adamiak M, Ratajczak J, Kucia M, Ratajczak MZ. Human haematopoietic stem/progenitor cells express several functional sex hormone receptors. J Cell Mol Med. 2014;20:134-46.

27. Zbucka-Kretowska M, Eljaszewicz A, Lipinska D, Grubczak K, Rusak M, Mrugacz G, Dabrowska M, Ratajczak MZ, Moniuszko M. Effective mobilization of very small embryonic-like stem cells and hematopoietic stem/progenitor cells but not endothelial progenitor cells by follicle-stimulating hormone therapy. Stem Cell Int. 2016; https://doi.org/10.1155/2016/8530207.

28. Zarate-Garcia L, Lane SI, Merriman JA, Jones KT. FACS-sorted putative oogonial stem cells from the ovary are neither DDX4-positive nor germ cells. Sci Rep. 2016:6:27991.

29. Guo K, Li CH, Wang XY, He DJ, Zheng P. Germ stem cells are active in postnatal mouse ovary under physiological conditions. Mol Hum Reprod. 2016;22:316-28

30. Zhang $C$, Wu J. Production of offspring from a germline stem cell line derived from prepubertal ovaries of germline reporter mice. Mol Hum Reprod. 2016;22(7):457-64.

31. Staniszewska AD, Pensa S, Caffarel MM, Anderson LH, Poli V, Watson CJ. Stat3 is required to maintain the full differentiation potential of mammary stem cells and the proliferative potential of mammary luminal progenitors PLoS One. 2012;7(12):e52608.

32. Guo M, Jan $L Y$, Jan $Y N$. Control of daughter cell fates during asymmetric division: interaction of Numb and notch. Neuron. 1996;17(1):27-41.

33. Shaikh A, Bhartiya D, Kapoor S, Nimkar H. Delineating the effects of 5fluorouracil and follicle-stimulating hormone on mouse bone marrow stem/ progenitor cells. Stem Cell Res Ther. 2016;7(1):59.

34. Bhartiya D, Sriraman K, Gunjal P, Modak H. Gonadotropin treatment augments postnatal oogenesis and primordial follicle assembly in adult mouse ovaries? J Ovarian Res. 2012;5(1):32.

35. Parte S, Bhartiya D, Manjramkar DD, Chauhan A, Joshi A. Stimulation of ovarian stem cells by follicle stimulating hormone and basic fibroblast growth factor during cortical tissue culture. J Ovarian Res. 2013;6(1):20.

36. Dunlop CE, Anderson RA. The regulation and assessment of follicular growth. Scand J Clin Lab Invest Suppl. 2014;244:13-7.

37. Lei L, Spradling AC. Female mice lack adult germ-line stem cells but sustain oogenesis using stable primordial follicles. Proc Natl Acad Sci U S A. 2013; 110(21):8585-90.
38. Bhartiya D, Sriraman K, Parte S, Patel H. Ovarian stem cells: absence of evidence is not evidence of absence. J Ovarian Res. 2013;6(1):65.

39. Smith P. Wilhelm D \& Rodgers RJ development of mammalian ovary. J Endocrinol. 2014;221(3):R145-61.

40. Lei L, Spradling AC. Mouse oocytes differentiate through organelle enrichment from sister cyst germ cells. Science. 2016;352(6281):95-9.

41. Auersperg N. The stem-cell profile of ovarian surface epithelium is reproduced in the oviductal fimbriae, with increased stem-cell marker density in distal parts of the fimbriae. Int J Gynecol Pathol. 2013;32(5):444-53.

42. Bhartiya D, Singh J. FSH-FSHR3-stem cells in ovary surface epithelium: basis for adult ovarian biology, failure, aging, and cancer. Reproduction. 2015; 149(1):35-48.

43. Virant-Klun I, Stimpfel M. Novel population of small tumour-initiating stem cells in the ovaries of women with borderline ovarian cancer. Sci Rep. 2016; 6:34730. https://doi.org/10.1038/srep34730.

44. Tisdall DJ, Watanabe K, Hudson NL, Smith P, McNatty KP. FSH receptor gene expression during ovarian follicle development in sheep. J Mol Endocrinol. 1995;15(3):273-81.

45. Oktay K, Briggs D, Gosden RG. Ontogeny of follicle-stimulating hormone receptor gene expression in isolated human ovarian follicles. J Clin Endocrinol Metab. 1997;82(11):3748-51.

46. Zheng W, Magid MS, Kramer EE, Chen YT. Follicle-stimulating hormone receptor is expressed in human ovarian surface epithelium and fallopian tube. Am J Pathol. 1996;148(1):47-53.

47. Parrott JA, Doraiswamy V, Kim G, Mosher R, Skinner MK. Expression and actions of both the follicle stimulating hormone receptor and the luteinizing hormone receptor in normal ovarian surface epithelium and ovarian cancer. Mol Cell Endocrinol. 2001;172(1-2):213-22.

48. Ji Q, Liu PI, Chen PK, Aoyama C. Follicle stimulating hormone-induced growth promotion and gene expression profiles on ovarian surface epithelial cells. Int J Cancer. 2004;112(5):803-14.

49. Patsoula E, Loutradis D, Drakakis $P$, Kallianidis K, Bletsa R, Michalas S. Expression of mRNA for the $\mathrm{LH}$ and $\mathrm{FSH}$ receptors in mouse oocytes and preimplantation embryos. Reproduction. 2001;121(3):455-61.

50. Minegishi T, Kameda T, Hirakawa T, Abe K, Tano M, Ibuki Y. Expression of gonadotropin and activin receptor messenger ribonucleic acid in human ovarian epithelial neoplasms. Clin Cancer Res. 2000;6(7):2764-70.

51. Li Y, Ganta S, Cheng C, Craig R, Ganta RR, Freeman LC. FSH stimulates ovarian cancer cell growth by action on growth factor variant receptor. Mol Cell Endocrinol. 2007;267(1-2):26-37.

52. Bose CK. Follicle stimulating hormone receptor in ovarian surface epithelium and epithelial ovarian cancer. Oncol Res. 2008;17(5):231-8.

53. Meduri G, Charnaux N, Driancourt MA, Combettes L, Granet P, Vannier B, Loosfelt $\mathrm{H}$, Milgrom E. Follicle-stimulating hormone receptors in oocytes? J Clin Endocrinol Metab. 2002;87(5):2266-76.

54. Sullivan RR, Faris BR, Eborn D, Grieger DM, Cino-Ozuna AG, Rozell TG. Follicular expression of follicle stimulating hormone receptor variants in the ewe. Reprod Biol Endocrinol. 2013;11:113.

55. Babu PS, Danilovich N, Sairam MR. Hormone-induced receptor gene splicing: enhanced expression of the growth factor type I follicle stimulating hormone receptor motif in the developing mouse ovary as a new paradigm in growth regulation. Endocrinology. 2001;142(1):381-9.

56. James K, Bhartiya D, Ganguly R, Kaushik A, Gala K, Metkari SM. Gonadotropin and steroid hormones regulate pluripotent very small embryonic-like stem cells in adult mouse uterine endometrium. Under review in reproductive sciences. 2017.

57. Davies BR, Finnigan DS, Smith SK, Ponder BA. Administration of gonadotropins stimulates proliferation of normal mouse ovarian surface epithelium. Gynecol Endocrinol. 1999;13(2):75-81.

58. Burdette JE, Kurley SJ, Kilen SM, Mayo KE, Woodruff TK. Gonadotropin induced superovulation drives ovarian surface epithelia proliferation in CD1 mice. Endocrinology. 2006;147(5):2338-45.

59. Stewart SL, Querec TD, Gruver BN, O'Hare B, Babb JS, Patriotis C. Gonadotropin and steroid hormones stimulate proliferation of the rat ovarian surface epithelium. J Cell Physiol. 2004;198(1):119-24.

60. Roy SK, Albee L. Requirement for follicle-stimulating hormone action in the formation of primordial follicles during perinatal ovarian development in the hamster. Endocrinology. 2000:141(12):4449-56.

61. Parte S, Bhartiya D, Patel H, Daithankar V, Chauhan A, Zaveri K, Hinduja I. Dynamics associated with spontaneous differentiation of ovarian stem cells in vitro. J Ovarian Res. 2014;7:25. 
62. Dierich A, Sairam MR, Monaco L, Fimia GM, Gansmuller A, LeMeur M, Sassone-Corsi P. Impairing follicle-stimulating hormone (FSH) signaling in vivo. Targeted disruption of the FSH receptor leads to aberrant gametogenesis and hormonal imbalance. Proc Natl Acad Sci U S A. 1998:95:13612-7.

63. Abel MH, Wootton AN, Wilkins V, Huhtaniemi I, Knight PG, Charlton HM. The effect of a null mutation in the follicle-stimulating hormone receptor gene on mouse reproduction. Endocrinology. 2000;141:1795-803.

64. O'Shaughnessy PJ, Dudley K, Rajapaksha WR. Expression of follicle stimulating hormone-receptor mRNA during gonadal development. Mol Cell Endocrinol. 1996;125:169-75.

65. Allan CM, Wang Y, Jimenez M, Marshan B, Spaliviero J, Illingworth P, Handelsman DJ. Follicle-stimulating hormone increases primordial follicle reserve in mature female hypogonadal mice. J Endocrinol. 2006;188:549-57.

66. Lei L, Jin S, Mayo KE, Woodruff TK. The interactions between the stimulatory effect of follicle-stimulating hormone and the inhibitory effect of estrogen on mouse primordial folliculogenesis. Biol Reprod. 2010;82:13-22.

67. Wu C, Xu B, Li X, Ma W, Zhang P, Chen X, Wu J. Tracing and characterizing the development of transplanted female Germline stem cells in vivo. Mol Ther. 2017:25(6):1408-19.

\section{Submit your next manuscript to BioMed Central} and we will help you at every step:

- We accept pre-submission inquiries

- Our selector tool helps you to find the most relevant journal

- We provide round the clock customer support

- Convenient online submission

- Thorough peer review

- Inclusion in PubMed and all major indexing services

- Maximum visibility for your research

Submit your manuscript at www.biomedcentral.com/submit 